\title{
A Review on the Role of miR-1246 in the Pathoetiology of Different Cancers
}

OPEN ACCESS

Edited by:

Wei Ye,

Guangdong Academy of Science,

China

Reviewed by:

Lincan Duan,

Third Affiliated Hospital of Kunming

Medical University, China Rezvan Noroozi,

Jagiellonian University, Poland

Sharanjot Saini,

University of California, San Francisco,

United States

*Correspondence:

Mohammad Taheri

mohammad_823@yahoo.com

Mohammad Samadian

mdsamadian@gmail.com

Specialty section:

This article was submitted to

RNA Networks and Biology,

a section of the journal

Frontiers in Molecular Biosciences

Received: 07 September 2021

Accepted: 22 November 2021

Published: 03 January 2022

Citation:

Ghafouri-Fard S, Khoshbakht T,

Hussen BM, Taheri $M$ and

Samadian M (2022) A Review on the

Role of miR-1246 in the Pathoetiology

of Different Cancers.

Front. Mol. Biosci. 8:771835.

doi: 10.3389/fmolb.2021.771835

\author{
Soudeh Ghafouri-Fard ${ }^{1}$, Tayyebeh Khoshbakht ${ }^{2}$, Bashdar Mahmud Hussen ${ }^{3,4}$, \\ Mohammad Taheri ${ }^{5 *}$ and Mohammad Samadian ${ }^{6 *}$
}

${ }^{1}$ Department of Medical Genetics, School of Medicine, Shahid Beheshti University of Medical Sciences, Tehran, Iran, ${ }^{2}$ Men's Health and Reproductive Health Research Center, Shahid Beheshti University of Medical Sciences, Tehran, Iran, ${ }^{3}$ Department of Pharmacognosy, College of Pharmacy, Hawler Medical University, Erbil, Iraq, ${ }^{4}$ Center of Research and Strategic Studies, Lebanese French University, Erbil, Iraq, ${ }^{5}$ Institute of Human Genetics, Jena University Hospital, Jena, Germany, ${ }^{6}$ Skull Base Research Center, Loghman Hakim Hospital, Shahid Beheshti University of Medical Sciences, Tehran, Iran

miR-1246 is a microRNA firstly recognized through application of a high throughput sequencing technique in human embryonic stem cells. Subsequent studies have shown the role of this microRNA in the carcinogenesis. miR-1246 has been found to exert oncogenic roles in colorectal, breast, renal, oral, laryngeal, pancreatic and ovarian cancers as well as melanoma and glioma. In lung, cervical and liver cancers, studies have reported contradictory results regarding the role of miR-1246. miR-1246 has been reported to regulate activity of RAF/MEK/ERK, GSK3 $\beta$, Wnt/ $\beta$-catenin, JAK/STAT, PI3K/AKT, THBS2/ MMP and $\mathrm{NOTCH} 2$ pathways. In addition to affecting cell cycle progression and proliferation, miR-1246 can influence stemness and resistance of cancer cells to therapeutics. In the current review, we describe the summary of in vitro and in vivo studies about the influence of miR-1246 in carcinogenesis in addition to studies that measured expression levels of miR-1246 in clinical samples.

Keywords: miRNA, MiR-1246, cancer, expression, biomarker, in vivo, in vitro, diagnosis

\section{INTRODUCTION}

miR-1246 has been firstly recognized through application of a high throughput sequencing technique in human embryonic stem cells (Morin et al., 2008). Subsequent studies have mapped the human miR-1246-coding gene, i.e., MIR1246 gene on chromosome 2q31.1 and reported the impact of p53 on the regulation of its expression (Zhang et al., 2011). Notably, the nucleotide sequence of the mature miR-1246 is identical to the central region of the RNU2-1 RNA (Xu et al., 2019), a small nuclear RNA which constructs the scaffold for establishment of the U2 complex in the spliceosome (Patel and Bellini, 2008).

Theoretically, the stem-loop TaqMan technique for detection of miR-1246 is expected to amplify both miR-1246 and RNA, U2 Small Nuclear 1 (RNU2-1). However, the poly-A tailing SYBR strategy can differentiate between miR-1246 and RNU2-1, since the sizes of the amplified fragments can be differentiated through assessment of their meting curves (Xu et al., 2019). Application of the latter strategy for assessment of miR-1246 expression in wild type and MIR1246 knockout pancreatic adenocarcinoma cells and exosomes originated from these cells has led to identification of a variant of the mature miR-1246 in exosomes that is transcribed from cellular RNU2-1 in an independent manner from Drosha and Dicer miRNA processing enzymes (Xu et al., 2019).

Several researchers have assessed expression of miR-1246 in different cancer cell lines using a variety of miRNA-profiling assays. Subsequently, they have performed functional assays to find the effects of miR-1246 up-regulation or silencing on proliferation and invasive properties of these cells. 


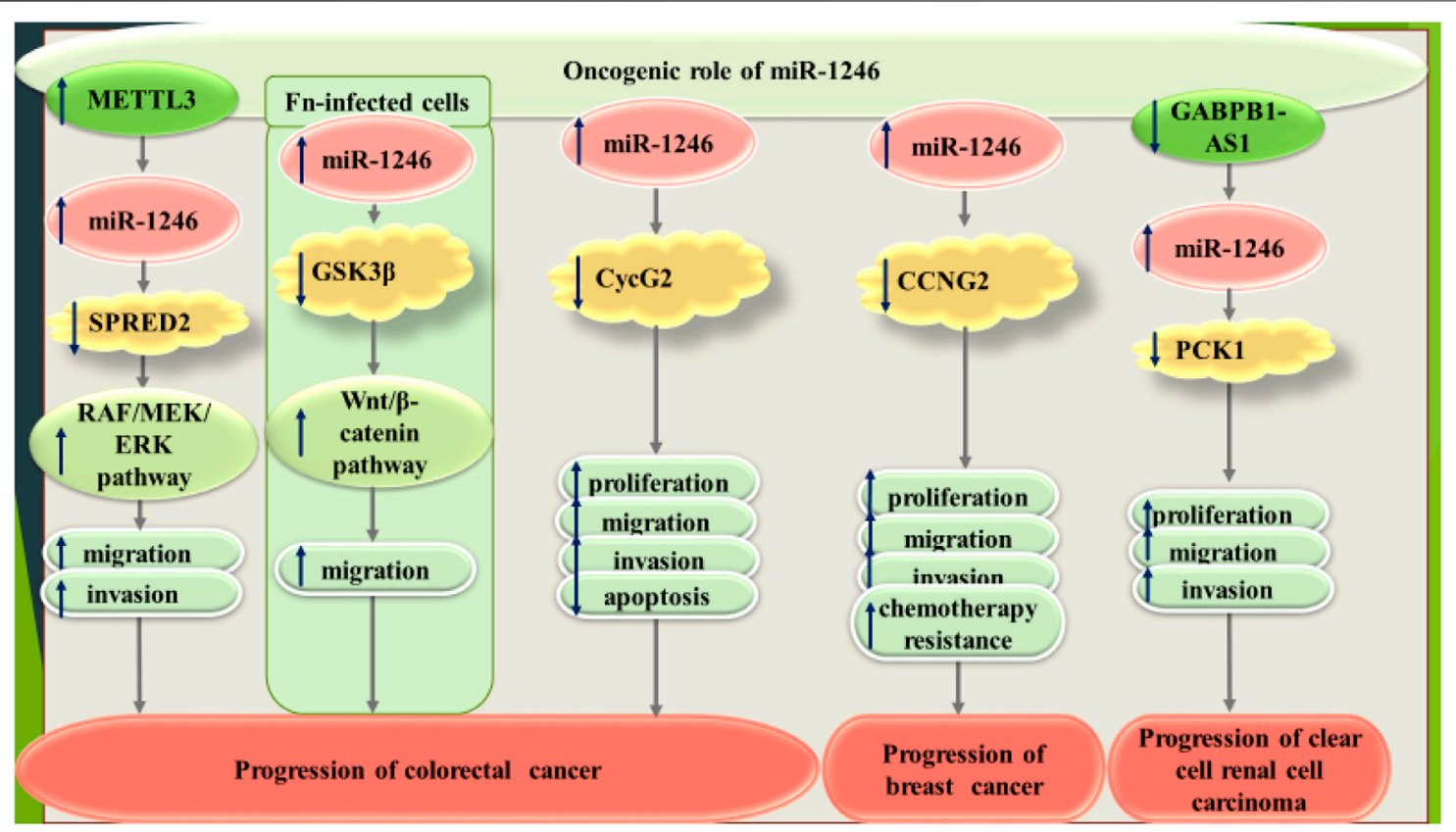

FIGURE 1 | Oncogenic role of miR-1246 in colorectal, breast and renal cancers.

Finally, the impact of this miRNA on tumor growth has been appraised in xenograft models constructed by injection of human cancer cell lines. In the current review, we describe the summary of these two types of studies in addition to those measured expression levels of miR-1246 in clinical samples.

\section{CELL LINE STUDIES}

Experiments in colorectal cancer cell lines have shown oncogenic role of miR-1246. In this type of cancer, the $m$ (6) $A$ methyltransferase METTL3 oncogene has been shown to increase methylation of pri-miR-1246 to enhance maturation of pri-miR-1246. Notably, miR-1246 has been predicted to suppress expression of the Sprouty Related EVH1 Domain Containing 2 (SPRED2) tumor suppressor, thus increasing activity of MAPK pathway (Peng et al., 2019).

Expression of miR-1246 has been found to be increased in exosomes derived from colorectal cancer cells infected with Fusobacterium nucleatum. In fact, this cancer-associated bacterium can enhance pro-metastatic behaviors through delivery of these exosomes into un-infected cells (Guo et al., 2021).

Expression of miR-1246 has also been reported to be surged in SW620, SW480, HCT116, HT29 and LOVO colorectal cancer cells, parallel with down-regulation of Cyclin G2 (CycG2). Experiments in HCT-116 and LOVO cells have verified CycG2 as the target of miR-1246. Up-regulation of miR-1246 has exerted pro-proliferative and pro-invasive effects in these cells, while its silencing has reversed these effects (Wang et al., 2016).

Exosomal and cellular levels of miR-1246 have been reported to be higher in organoid lines generated from colorectal cancer compared with organoid lines from colorectal adenomas. Consistent with this finding, miR-1246 up-regulation and down-regulation have enhanced reduced proliferation of an adenocarcinoma cell line, respectively (Nagai et al., 2021).

Another experiment in breast cancer cells has demonstrated high levels of miR-1246 in metastatic breast cancer cells compared with both non-metastatic cancer cells and nonneoplastic breast cells. miR-1246-containing exosomes from metastatic breast cancer cells can alter viability, migratory potential and chemoresistant phenotype of non-malignant breast cells. Functionally, miR-1246 suppresses expression of Cyclin G2 (Li et al., 2017).

In renal cell carcinoma cells, miR-1246 has an oncogenic effect through suppressing expression of PCK1. Notably, the tumor suppressor long non-coding RNA (lncRNA) GABPB1-AS1 has been shown to sponge miR-1246 in these cells (Gao et al., 2020).

Figure 1 shows the oncogenic role of miR-1246 in colorectal, breast and renal cancers.

miR-1246 has been demonstrated to increase the migration and invasive aptitudes of A549 adenocarcinomic human alveolar basal epithelial cells. In addition, miR-1246 could enhance epithelial-mesenchymal transition (EMT) of lung cancer cells. This miRNA could decrease levels of E-cadherin, while enhancing vimentin and TGF- $\beta$ levels. Functionally, miR-1246 can target $3^{\prime}$ untranslated region of GSK-3 $\beta$, thus regulating activity of Wnt/ $\beta$-catenin pathway (Yang et al., 2019).

Yuan et al. have investigated the impact of ionizing radiation (IR)-induced extracellular miRNAs on proliferation and radioresistance of A549 adenocarcinomic cells. They have reported particular abundance of miR-1246 outside of cells compared with its levels inside the cells. Irradiation could increase expression levels of miR-1246 in A549 and H446 cells 


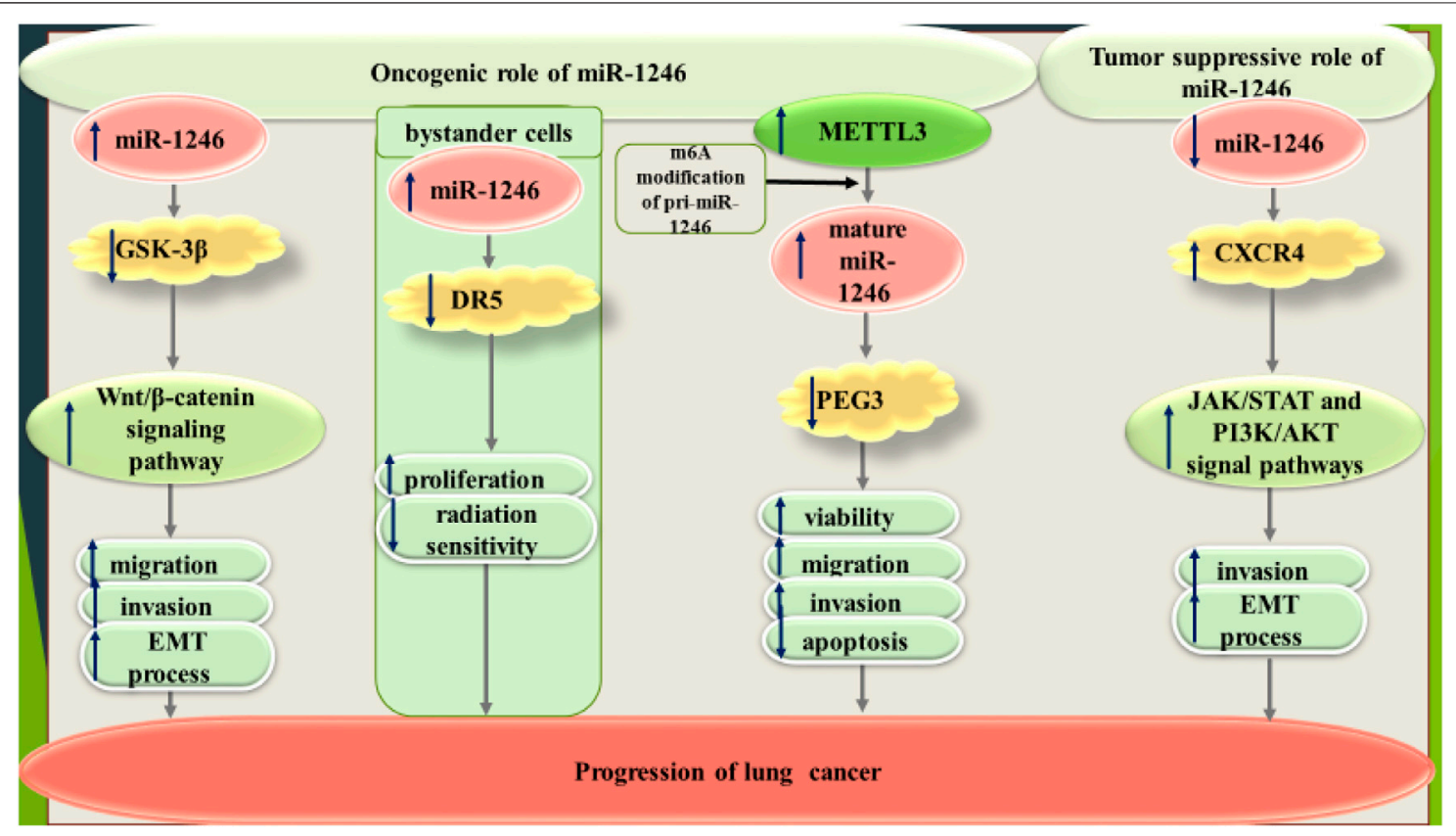

FIGURE 2 | Dual roles of miR-1246 in lung cancer.

in dose- and time-dependent manners. Extracellular miR-1246 has been shown to be transferred from donor cells to recipients through a non-exosome associated route enhancing proliferation and resistance of A549 cells to irradiation. Functionally, miR1246 reduces expression of death receptor 5 (DR5) (Yuan et al., 2016).

miR-1246 has been among up-regulated miRNAs in the sphereforming cells compared with the parental A549 and HCC1588 cells. Suppresion of miR-1246 has led to reduction of levels stemness and EMT markers in these cells. Moreover, anti-miR-1246 could suppress proliferation, sphere-formation, colony forming ability and invasiveness of lung cancer cells (Kim et al., 2016). Similarly, Huang et al. have reported up-regulation of miR-1246 and METTL3 in A549 and H1299 cells, parallel with down-regulation of PEG3. METTL3 has been shown to affect m6A marks of miR-1246, therefore increasing expression of miR-1246. Cumulatively, m6A methyltransferase METTL3 modifies the m6A marks of miR-1246 to up-regulates miR-1246 and subsequently increase progression of lung cancer (Huang et al., 2021).

Contrary to these studies, $\mathrm{Xu}$ et al. have reported downregulation of miR-1246 in A549, H1650 and H1299 cell lines compared to a normal human bronchial epithelial cell line. MiR1246 overexpression remarkably inhibited cell invasion as well as up-regulated E-cadherin expression and down-regulated N-cadherin, Vimentin, ZEB1 and Snail expressions in A549 cells. Further studies have confirmed CXCR4 as a target gene of miR-1246, and CXCR4 silence significantly abolished the promotion effect of miR-1246 suppression on cell invasion and EMT process in A549 cells. Besides, miR-1246 blocked JAK/STAT and PI3K/AKT signal pathways by regulation of CXCR4 (Xu et al., 2018). Figure 2 shows dual roles of miR1246 in lung cancer.
In SiHa HPV16-positive cervical cancer cell line, HPV16 E6 silencing has led to enhancement of miR-1246 expression, thus down-regulation of miR-1246 target DYRK1A. Meanwhile, overexpression of HPV16 E6 in HPV-negative C33A cell line has resulted in down-regulation of miR-1246 (Yang et al., 2015). Another study has shown that miR-1246 increases proliferation, invasiveness and migratory potential of $\mathrm{SiHa}$ cells through inhibition of expression of thrombospondin 2 (Chen et al., 2014). miR-1246 has also been among up-regulated miRNAs in radioresistant cervical cancer cells. Expression of this miRNA could be enhanced by irradiation of cervical cancer cells. Upregulation of miR-1246 has increased survival of cervical cancer cells upon irradiation (Zhang et al., 2013). Figure 3 shows dual roles of miR-1246 in cervical cancer.

Experiments in a co-culture model of hepatic stellate cells (HSCs) and hepatocellular carcinoma cells have shown that expression of miR-1246 is activated by HSCs. miR-1246 has been shown to target RORa. Up-regulation of miR-1246 or silencing of RORa has promoted proliferation, invasive properties, and metastatic aptitude of hepatocellular cancer cells through activation of $\mathrm{Wnt} / \beta$-catenin pathway and enhancement of EMT (Huang J.-L. et al., 2020). Another study has shown that miR-1246 increases invasiveness of hepatocellular carcinoma cells via modulation of CADM1 expression (Sun et al., 2014). Moreover, miR-1246 has been reported to promote stemness features such as self-renewal, resistance to therapeutics, tumorigenic potential, and metastasis through enhancing activity of $\mathrm{Wnt} / \beta$-catenin pathway. This effect is mediated through down-regulation of expression levels of AXIN2 and GSK3 $\beta$. Oct 4 has been identified as the direct regulator of miR-1246 expression which activates $\beta$-catenin in hepatic cancer stem cells (Chai et al., 2016). 


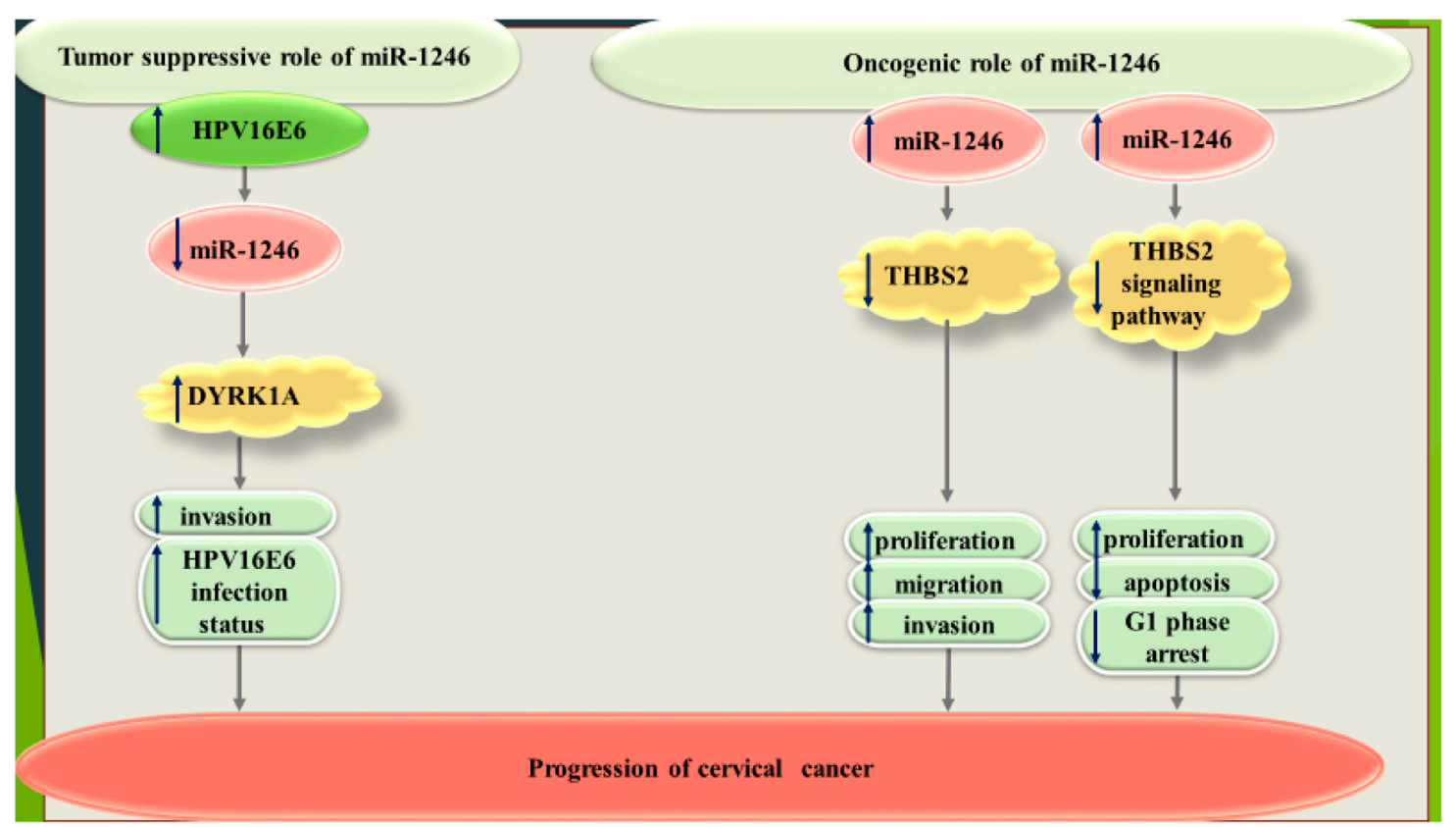

FIGURE 3 | Dual roles of miR-1246 in cervical cancer.

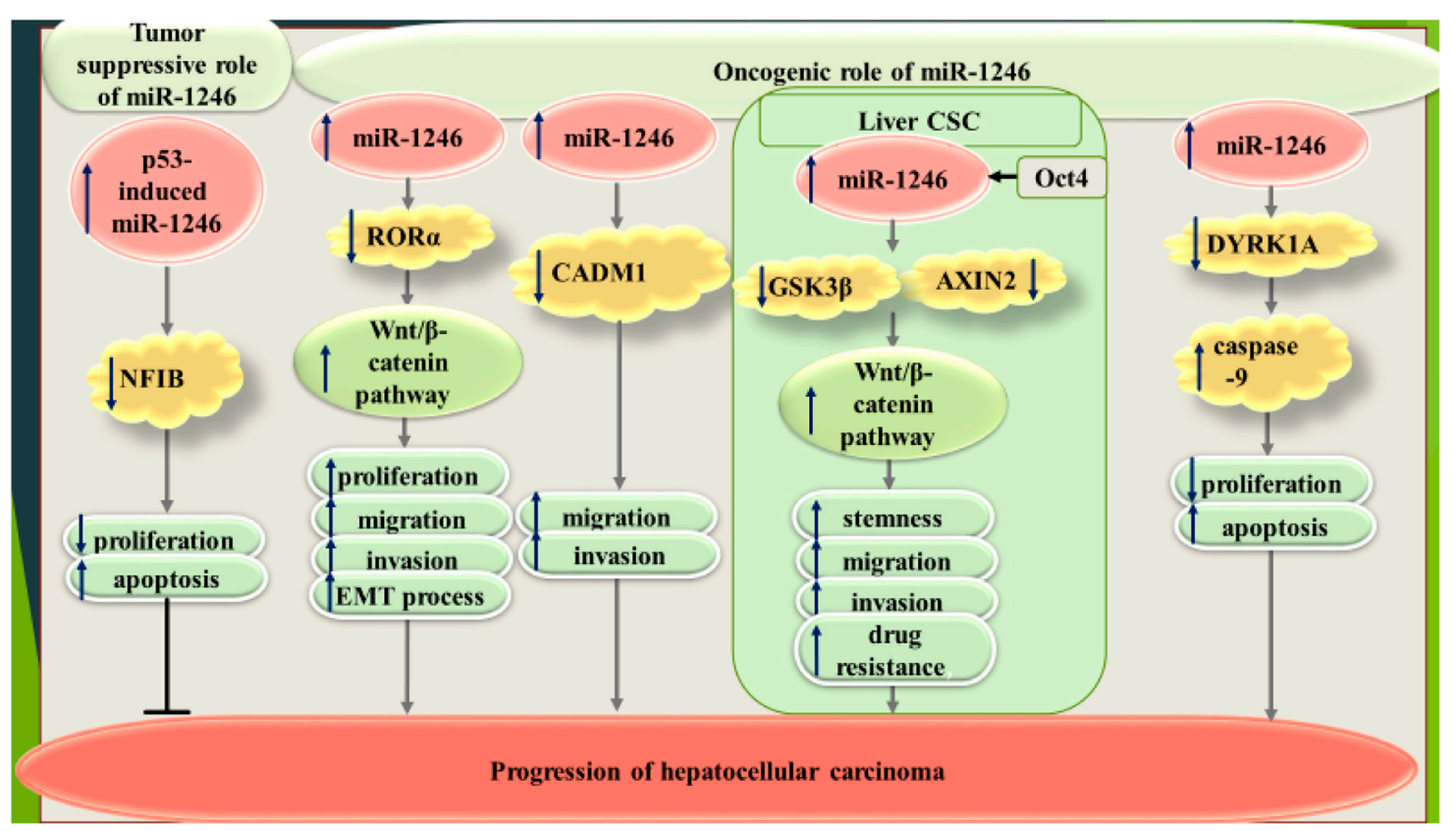

FIGURE 4 | Dual roles of miR-1246 in hepatocellular carcinoma.

On the other hand, Zhang et al. have shown that expression of miR-1246 is induced by p53. This miRNA has been shown to inhibit proliferation of hepatocellular carcinoma cells through influencing expression of NFIB (Zhang et al., 2015). Figure 4 shows dual roles of miR-1246 in hepatocellular carcinoma.
In oral squamous cell carcinoma, miR-1246 has been shown to target CCNG2 to facilitate stemness properties and induce resistance to chemotherapy (Lin et al., 2018). Moreover, exosomal transfer of this miRNA has enhanced cell motility and invasiveness of oral squamous cell carcinoma cells through targeting DENND2D (Sakha et al., 2016). Consistent 


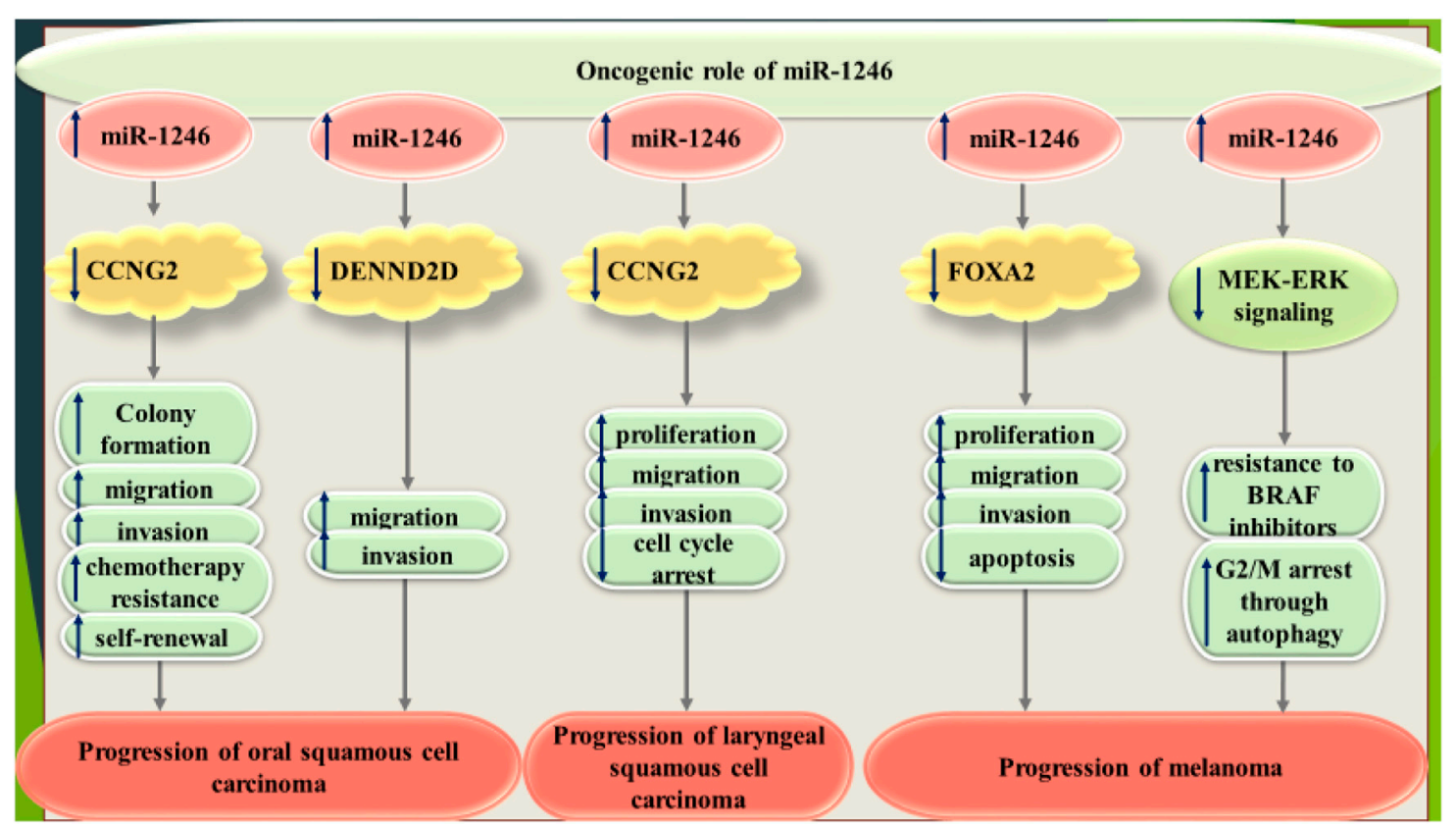

FIGURE 5 | Oncogenic role of miR-1246 in oral and laryngeal squamous cell carcinomas and melanoma.

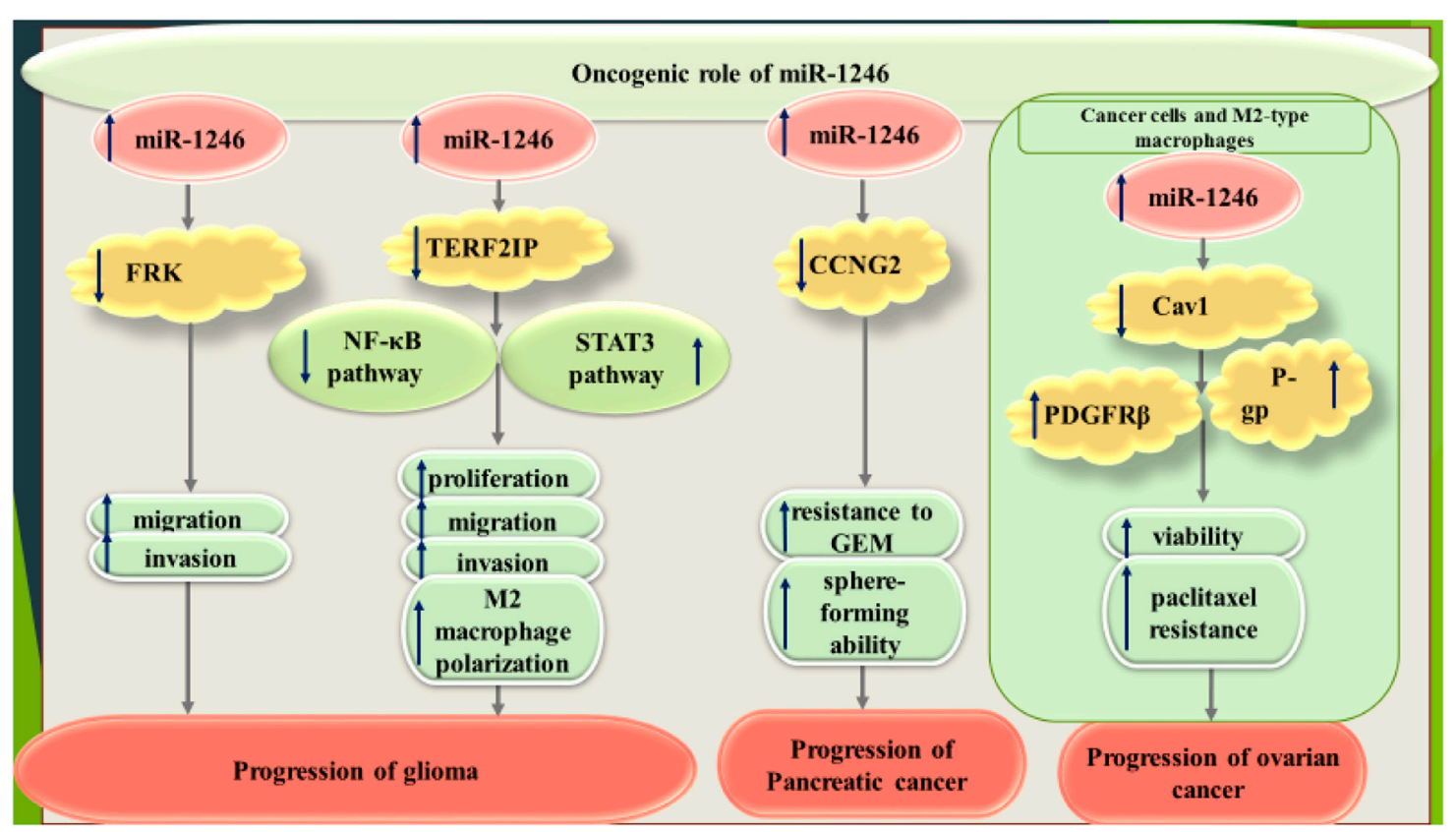

FIGURE 6 | Oncogenic role of miR-1246 in glioma, pancreatic cancer and ovarian cancer.

with this finding, small extracellular vesicles originated from laryngeal squamous cell carcinoma cells have been shown to enter into neighboring cells. Lack of miR-1246 in these vesicles abolished development of this kind of cancer. miR-1246 content of small vesicles could participate in the pathoetiology of laryngeal squamous cell carcinoma through suppressing CCNG2 expression
(Huang Q. et al., 2020). miR-1246 is involved in the progression of melanoma via changing expression levels FOXA2 (Yu et al., 2020). Moreover, miR-1246 has been shown to increase resistance of melanoma cells to BRAF inhibitors (Kim et al., 2017). Figure 5 shows oncogenic role of miR-1246 in oral and laryngeal squamous cell carcinomas and melanoma. 
TABLE 1 | Outlines of in vitro studies about function of miR-1246 ( $\Delta$ : knock-down or deletion, FN: Fusobacterium nucleatum, sEV: Small extracellular vesicle, GEM: gemcitabine).

\begin{tabular}{|c|c|c|c|c|}
\hline Tumor type & $\begin{array}{c}\text { Targets/Regulators and signaling } \\
\text { pathways }\end{array}$ & Cell line & Function & References \\
\hline \multirow[t]{3}{*}{ Colorectal cancer } & $\begin{array}{l}\text { m6A, METTL3, SPRED2, RAF/MEK/ERK } \\
\text { pathway }\end{array}$ & $\begin{array}{l}\text { LoVo, HCT116, CaCo2, DLD- } \\
\text { 1, HT-29, NCM460 }\end{array}$ & $\begin{array}{l}\Delta \text { METTL3: } \downarrow \text { migration, } \downarrow \text { invasion } \\
\uparrow \text { METTL3: } \uparrow \text { migration, } \uparrow \text { invasion }\end{array}$ & $\begin{array}{l}\text { Peng et al. } \\
\text { (2019) }\end{array}$ \\
\hline & GSK3 $\beta$, Wnt $/ \beta$-catenin pathway & HCT116, SW480 & $\begin{array}{l}\text { Fn infection: } \uparrow \text { secretion of exosomes } \\
\text { Fn-Ex treatment: } \uparrow \text { migration, } \uparrow \text { wound } \\
\text { closure } \\
\uparrow \text { miR-1246: } \uparrow \text { migration, } \uparrow \text { wound closure }\end{array}$ & Guo et al. (2021) \\
\hline & - & HT-29 & $\begin{array}{l}\Delta \text { miR-1246: } \downarrow \text { proliferation } \\
\uparrow \text { miR-1246: } \uparrow \text { proliferation }\end{array}$ & $\begin{array}{l}\text { Nagai et al. } \\
(2021)\end{array}$ \\
\hline \multirow[t]{4}{*}{ Lung cancer } & GSK-3 $\beta$, Wnt/ $\beta$-catenin signaling pathway & A549 & $\begin{array}{l}\Delta \text { miR-1246: } \downarrow \text { migration, } \downarrow \text { invasion, } \downarrow \text { EMT } \\
\text { process } \\
\uparrow \text { miR-1246: } \uparrow \text { migration, } \uparrow \text { invasion, } \uparrow \text { EMT } \\
\text { process }\end{array}$ & $\begin{array}{l}\text { Yang et al. } \\
\text { (2019) }\end{array}$ \\
\hline & - & A549, HCC1588 & $\begin{array}{l}\Delta \text { miR-1246: } \downarrow \text { proliferation, } \downarrow \text { stemness, } \downarrow \\
\text { EMT process, } \downarrow \text { sphere-formation, } \downarrow \text { colony } \\
\text { formation, } \downarrow \text { invasion }\end{array}$ & Kim et al. (2016) \\
\hline & $\begin{array}{l}\text { CXCR4, JAK/STAT and PIBK/AKT signal } \\
\text { pathways }\end{array}$ & $\begin{array}{l}\text { A549, H1650, H1299, } \\
\text { 16HBE140 }\end{array}$ & $\uparrow$ miR-1246: $\downarrow$ invasion, $\downarrow$ EMT process & Xu et al. (2018) \\
\hline & METTL3, m6A, PEG3 & A549, H1299, H520, H1975 & $\begin{array}{l}\Delta \text { METTL3: } \downarrow \text { viability, } \downarrow \text { colony formation, } \downarrow \\
\text { migration, } \downarrow \text { invasion, } \uparrow \text { apoptosis } \\
\uparrow \text { miR-1246: } \uparrow \text { migration, } \uparrow \text { invasion, } \downarrow \\
\text { apoptosis }\end{array}$ & $\begin{array}{l}\text { Huang et al. } \\
\text { (2021) }\end{array}$ \\
\hline Cervical cancer & HPV16E6, DYRK1A & HeLa, SiHa, Caski, C33A & $\Delta$ miR-1246: $\uparrow$ invasion $\uparrow$ miR-1246: $\downarrow$ invasion & $\begin{array}{l}\text { Yang et al. } \\
\text { (2015) }\end{array}$ \\
\hline Breast cancer & CCNG2 & $\begin{array}{l}\text { MCF-7, MDA-MB-231, MCF- } \\
\text { 10A, HMLE }\end{array}$ & $\begin{array}{l}\uparrow \text { miR-1246: } \uparrow \text { proliferation, } \uparrow \text { migration, } \uparrow \\
\text { invasion, } \uparrow \text { chemotherapy resistance }\end{array}$ & Li et al. (2017) \\
\hline \multirow[t]{6}{*}{$\begin{array}{l}\text { Hepatocellular } \\
\text { carcinoma }\end{array}$} & $\mathrm{ROR} \alpha, \mathrm{Wnt} / \beta$-catenin pathway & $\begin{array}{l}\text { HSCs, PLC, MHCC } 97 \mathrm{H} \text {, } \\
\text { HCCLM3 }\end{array}$ & $\begin{array}{l}\uparrow \text { miR-1246: } \uparrow \text { proliferation, } \uparrow \text { migration, } \uparrow \\
\text { invasion, } \uparrow \text { EMT process }\end{array}$ & $\begin{array}{l}\text { Huang et al. } \\
\text { (2020a) }\end{array}$ \\
\hline & CADM1 & $\begin{array}{l}\text { HepG2, SMMC7721 and } \\
\text { BEL7402 }\end{array}$ & $\begin{array}{l}\Delta \text { miR-1246: } \downarrow \text { migration, } \downarrow \text { invasion } \\
\uparrow \text { miR-1246: } \uparrow \text { migration, } \uparrow \text { invasion }\end{array}$ & Sun et al. (2014) \\
\hline & $\mathrm{p} 53, \mathrm{NFIB}$ & $\begin{array}{l}\text { HepG2, Hep3B, Huh7, C3A, } \\
\text { PLC, LO2, SUN387 }\end{array}$ & $\begin{array}{l}\Delta \text { miR-1246: } \downarrow \\
\text { Proliferation } \\
\uparrow \text { miR-1246: } \uparrow \text { proliferation }\end{array}$ & $\begin{array}{l}\text { Zhang et al. } \\
\text { (2015) }\end{array}$ \\
\hline & $\begin{array}{l}\text { Oct4, AXIN2, GSK3 } \beta \text {, Wnt/ } \beta \text {-catenin } \\
\text { pathway }\end{array}$ & Hep3B, Huh7 & $\begin{array}{l}\Delta \text { miR-1246: } \downarrow \text { invasion, } \downarrow \text { migration, } \downarrow \text { ability } \\
\text { to initiate hepatosphere formation, } \downarrow \text { self- } \\
\text { renewal, } \uparrow \text { sensitization to } 5 \text {-fluorouracil, } \\
\text { cisplatin and sorafenib }\end{array}$ & Chai et al. (2016) \\
\hline & Galectin-9, DYRK1A, caspase-9 & Li-7, Huh7, HLE & $\begin{array}{l}\uparrow \text { galectin-9: } \downarrow \text { Proliferation, } \uparrow \text { apoptosis, } \uparrow \\
\text { miR-1246 } \\
\uparrow \text { miR- } 1246+\text { galectin-9 treatment in Li-7 } \\
\text { cells: } \downarrow \text { Proliferation, } \uparrow \text { apoptosis }\end{array}$ & $\begin{array}{l}\text { Fujita et al. } \\
\text { (2015) }\end{array}$ \\
\hline & - & BEL-7402 & $\begin{array}{l}\text { bafilomycin A1-treatment: } \downarrow \\
\text { Proliferation, } \downarrow \text { invasion, } \uparrow \text { miR-1246 }\end{array}$ & Lu et al. (2015) \\
\hline
\end{tabular}

(Continued on following page) 
TABLE 1 | (Continued) Outlines of in vitro studies about function of miR-1246 ( $\Delta$ : knock-down or deletion, FN: Fusobacterium nucleatum, sEV: Small extracellular vesicle, GEM: gemcitabine).

\begin{tabular}{|c|c|c|c|c|}
\hline Tumor type & $\begin{array}{c}\text { Targets/Regulators and signaling } \\
\text { pathways }\end{array}$ & Cell line & Function & References \\
\hline \multirow[t]{2}{*}{$\begin{array}{l}\text { Oral squamous cell } \\
\text { carcinoma }\end{array}$} & CCNG2 & OC3, FaDu & $\begin{array}{l}\Delta \text { miR-1246: } \downarrow \text { migration, } \downarrow \text { invasion, } \downarrow \text { self- } \\
\text { renewal, } \downarrow \text { colony formation, } \downarrow \\
\text { chemoresistance } \\
\uparrow \text { miR-1246: } \uparrow \text { invasion, } \uparrow \text { colony formation, } \uparrow \\
\text { number of spheres, } \uparrow \text { stemness }\end{array}$ & Lin et al. (2018) \\
\hline & DENND2D & HOC313-P, TSU, HeLa & $\begin{array}{l}\uparrow \text { miR-1246: } \uparrow \text { migration, } \uparrow \text { invasion, did not } \\
\text { affect growth }\end{array}$ & $\begin{array}{l}\text { Sakha et al. } \\
(2016)\end{array}$ \\
\hline $\begin{array}{l}\text { Laryngeal squamous } \\
\text { Cell carcinoma }\end{array}$ & CCNG2 & Hep-2, AMC-HN-8 & $\begin{array}{l}\Delta \text { miR-1246 in sEV: } \downarrow \\
\text { Proliferation, } \downarrow \text { migration, } \downarrow \text { invasion, } \uparrow \text { cell } \\
\text { cycle arrest }\end{array}$ & $\begin{array}{l}\text { Huang et al. } \\
\text { (2020b) }\end{array}$ \\
\hline \multirow[t]{3}{*}{ Melanoma } & FOXA2 & HEM, A375, A2058 & $\begin{array}{l}\Delta \text { miR-1246 in sEV: } \downarrow \\
\text { Proliferation, } \downarrow \text { migration, } \downarrow \text { invasion, } \uparrow \\
\text { apoptosis } \\
\uparrow \text { miR-1246: } \uparrow \text { proliferation, } \uparrow \text { migration, } \uparrow \\
\text { invasion, } \downarrow \text { apoptosis }\end{array}$ & Yu et al. (2020) \\
\hline & MEK-ERK signaling & $\begin{array}{l}\text { A375P BRAF V600E, A375P/ } \\
\text { Mdr, SK-MEL-2 BRAF-WT }\end{array}$ & $\begin{array}{l}\uparrow \mathrm{miR}-1246: \uparrow \text { resistance to BRAF inhibitors, } \uparrow \\
\text { G2/M arrest through autophagy }\end{array}$ & Kim et al. (2017) \\
\hline & IL-6, STAT3, Akt & HMVECs, A375, A375SM & $\uparrow$ miR-1246: $\uparrow$ resistance to 5-FU & Torii et al. (2021) \\
\hline \multirow[t]{2}{*}{ Glioma } & FRK & H-GDEs & $\uparrow \mathrm{miR}-1246: \uparrow$ migration, $\uparrow$ invasion & $\begin{array}{l}\text { Qian et al. } \\
\text { (2021a) }\end{array}$ \\
\hline & TERF2IP, STAT3 pathway, NF-кB pathway & U87MG, U251, U937 & $\begin{array}{l}\uparrow \text { miR-1246: } \uparrow \text { proliferation, } \uparrow \text { migration, } \uparrow \\
\text { invasion, } \uparrow \text { M2 macrophage polarization }\end{array}$ & Qian et al. (2020) \\
\hline Pancreatic cancer & CCNG2 & Panc1, Panc1-P & $\begin{array}{l}\uparrow \text { miR-1246: } \uparrow \text { resistance to GEM, } \uparrow \text { sphere- } \\
\text { forming ability }\end{array}$ & $\begin{array}{l}\text { Hasegawa et al. } \\
\text { (2014) }\end{array}$ \\
\hline \multirow[t]{2}{*}{ Ovarian cancer } & Cav1, PDGFR $\beta$, P-gp & $\begin{array}{l}\text { eyA8, SKOV3-ip1, A2780, } \\
\text { HeyA8-MDR, SKOV3-TR, } \\
\text { A2780-CP20, HIO180 }\end{array}$ & $\Delta$ miR-1246: $\downarrow$ paclitaxel resistance, $\downarrow$ viability & $\begin{array}{l}\text { Kanlikilicer et al. } \\
\text { (2018) }\end{array}$ \\
\hline & - & $\mathrm{HO}-8910$ & $\begin{array}{l}\text { bafilomycin A1-treatment: } \downarrow \\
\text { Proliferation, } \downarrow \text { invasion, } \uparrow \text { miR-1246 }\end{array}$ & Lu et al. (2015) \\
\hline $\begin{array}{l}\text { Clear cell renal cell } \\
\text { carcinoma }\end{array}$ & GABPB1-AS1, PCK1 & $786-0$ and caki-1 & $\begin{array}{l}\uparrow \text { GABPB1-AS1: } \downarrow \\
\text { Proliferation, } \downarrow \text { migration, } \downarrow \text { invasion }\end{array}$ & Gao et al. (2020) \\
\hline \multirow[t]{2}{*}{$\begin{array}{l}\text { Acute myeloid } \\
\text { leukemia }\end{array}$} & LRIG1, STAT3 pathway & LSCs & $\begin{array}{l}\uparrow \text { miR-1246 + LSCs co-cultured with EVs: } \uparrow \\
\text { viability, } \uparrow \text { colony formation, } \downarrow \text { apoptosis, } \downarrow \\
\text { differentiation }\end{array}$ & $\begin{array}{l}\text { Chen et al. } \\
\text { (2021a) }\end{array}$ \\
\hline & Raptor/mTOR pathway & $\begin{array}{l}\text { Molm-14, HL-60, U-937, } \\
\text { LT-HSC }\end{array}$ & $\begin{array}{l}\uparrow \text { miR-1246: } \downarrow \text { protein synthesis, } \uparrow \\
\text { quiescence }\end{array}$ & $\begin{array}{l}\text { Abdelhamed } \\
\text { et al. (2019) }\end{array}$ \\
\hline Leukemia & $\begin{array}{l}\text { AXIN2, GSK-3 } \beta, \text { Wnt } / \beta \text {-catenin } \\
\text { pathway, P-gp }\end{array}$ & $\begin{array}{l}\text { K562, HL-60 cells and drug- } \\
\text { resistant K562/ADM, HL- } \\
60 / R S\end{array}$ & $\begin{array}{l}\Delta \text { miR-1246: } \downarrow \text { Proliferation, } \uparrow \text { apoptosis, } \uparrow \\
\text { chemo-sensitivity }\end{array}$ & Xie et al. (2021) \\
\hline $\begin{array}{l}\text { T cell acute } \\
\text { lymphoblastic } \\
\text { leukemia (T-ALL) }\end{array}$ & NOTCH2 Pathway & T-ALL & $\begin{array}{l}\Delta \mathrm{miR}-1246: \downarrow \text { Proliferation } \\
\uparrow \mathrm{miR}-1246: \uparrow \text { Proliferation }\end{array}$ & Luo et al. (2018) \\
\hline Gastric cancer & $\begin{array}{l}\text { Oxidative stress response, axon guidance } \\
\text { mediated by netrin, salvage pyrimidine } \\
\text { deoxyribonucleotides }\end{array}$ & $\mathrm{NCl}-\mathrm{N} 87$ & cisplatin treatment: $\uparrow \mathrm{miR}-1246$ & Yin et al. (2019) \\
\hline Gallbladder cancer & - & G415 & $\begin{array}{l}\Delta \text { miR-1246: } \downarrow \text { Proliferation, } \downarrow \text { invasion, } \uparrow \\
\text { apoptosis } \\
\uparrow \text { miR-1246: } \uparrow \text { Proliferation, } \uparrow \text { invasion, } \downarrow \\
\text { apoptosis }\end{array}$ & Ueta et al. (2021) \\
\hline Sarcoma & - & LP6, LPS12 & $\uparrow \mathrm{miR}-1246: \uparrow$ Proliferation & $\begin{array}{l}\text { Kohama et al. } \\
(2021)\end{array}$ \\
\hline
\end{tabular}

Exosomes originated from glioma cell cultures under hypoxic conditions could shuttle miR-1246 to normoxic glioma cells and enhance their migratory potential and invasiveness (Qian M. et al., 2021). Another study has shown the impact of these exosomes in induction of polarization of macrophages into M2 phenotype through targeting TERF2IP and subsequent influence on the activities of STAT3 and NF- $\mathrm{KB}$ signaling (Qian et al., 2020).
In pancreatic cancer, miR-1246 could increase chemoresistance and stemness through modulation of CCNG2 (Hasegawa et al., 2014).

Finally, in ovarian cancer, miR-1246 can confer resistance to chemotherapeutics through influencing Cav1/p-gp/M2-type macrophages (Kanlikilicer et al., 2018).

Figure 6 shows the oncogenic role of miR-1246 in glioma, pancreatic cancer and ovarian cancer. 
TABLE 2 | Outline of studies about the function of miR-1246 in animal models ( $\Delta$ : knock-down or deletion, PDX: derived orthotopic xenograft, NOD-SCID: non-obese diabetic/severe combined immunodeficiency, NSG: NOD Cg-Prkdcscid II2rgtm1Wj//SzJ).

\begin{tabular}{|c|c|c|c|}
\hline Tumor type & Animal models & Results & References \\
\hline \multirow[t]{2}{*}{ Colorectal cancer } & Male BALB/c nude mice & $\triangle$ METTL3: $\downarrow$ metastasis & Peng et al. (2019) \\
\hline & BALB/c nude mice & $\Delta$ miR-1246 in Fn-Ex group: $\downarrow$ metastasis & Guo et al. (2021) \\
\hline Lung cancer & Female BALB/c nude mice & $\begin{array}{l}\triangle \text { METTL3: } \downarrow \text { tumor volume, } \downarrow \text { tumor weight } \\
\uparrow \text { miR-1246: } \uparrow \text { tumor volume, } \uparrow \text { tumor weight }\end{array}$ & Huang et al. (2021) \\
\hline Cervical cancer & Athymic BALB/c nude mice & $\Delta$ miR-1246: $\downarrow$ tumor volume, $\downarrow$ tumor growth & Du et al. (2019) \\
\hline Prostate cancer & Nude mice & $\uparrow$ miR-1246 in xenograft tissues: $\downarrow$ tumor growth & $\begin{array}{l}\text { Bhagirath et al. } \\
(2018)\end{array}$ \\
\hline Breast cancer & Plasma of a PDX mouse & $\begin{array}{l}\text { miR-1246 was higher in the plasma exosomes of patient-PDX } \\
\text { mice compared to control mice }\end{array}$ & $\begin{array}{l}\text { Hannafon et al. } \\
(2016)\end{array}$ \\
\hline \multirow{3}{*}{$\begin{array}{l}\text { Hepatocellular } \\
\text { carcinoma }\end{array}$} & Male BALB/c-nu/nu mice & $\uparrow \mathrm{miR}-1246: \uparrow$ tumor growth, $\uparrow$ metastasis & Huang et al. (2020a) \\
\hline & Male BALB/c nude or NOD-SCID mice & $\Delta$ miR-1246: $\downarrow$ tumor initiation, $\downarrow$ tumor volume, $\downarrow$ metastasis & Chai et al. (2016) \\
\hline & Female athymic BALB/c-nu/nu mice & $\begin{array}{l}\uparrow \text { galectin-9: } \downarrow \text { tumor growth of Li-7 cells, } \uparrow \text { apoptosis, } \uparrow \text { miR- } \\
1246\end{array}$ & Fujita et al. (2015) \\
\hline \multirow{2}{*}{$\begin{array}{l}\text { Oral squamous cell } \\
\text { carcinoma }\end{array}$} & BALB/c nude mice & $\Delta \mathrm{miR}-1246: \downarrow$ tumor size & Lin et al. (2018) \\
\hline & & $\uparrow \operatorname{miR}-1246: \uparrow$ tumor growth & \\
\hline Glioma & Male nude mice & $\uparrow \mathrm{miR}-1246: \uparrow$ proliferation, $\uparrow \mathrm{M} 2$ macrophage polarization & Qian et al. (2020) \\
\hline Pancreatic cancer & $\begin{array}{l}\text { Female non-obese mice with diabetes/severe } \\
\text { combined immunodeficiency }\end{array}$ & $\uparrow$ miR-1246 in Panc1-P-I-OE: $\uparrow$ tumourigenicity & $\begin{array}{l}\text { Hasegawa et al. } \\
(2014)\end{array}$ \\
\hline Ovarian cancer & Nude mice & $\begin{array}{l}\Delta \text { miR-1246 + chemotherapy: } \downarrow \text { tumor weight, } \downarrow \text { macrophages } \\
\text { recruited by tumors }\end{array}$ & $\begin{array}{l}\text { Kanlikilicer et al. } \\
\text { (2018) }\end{array}$ \\
\hline Acute myeloid & NOD/SCID mice & $\downarrow$ EVs-miR-1246: $\downarrow$ tumor volume, $\downarrow$ tumor weight & Chen et al. (2021a) \\
\hline leukemia (AML) & NSG and C57BL/6J mice & $\uparrow \mathrm{miR}-1246: \uparrow$ quiescence & $\begin{array}{l}\text { Abdelhamed et al. } \\
\text { (2019) }\end{array}$ \\
\hline Leukemia & Male BALB/c nude mice & $\begin{array}{l}\Delta \text { miR-1246: } \downarrow \text { tumor volume, } \downarrow \text { tumor weight, } \downarrow \text { chemotherapy } \\
\text { resistance }\end{array}$ & Xie et al. (2021) \\
\hline
\end{tabular}

Table 1 shows the outlines of in vitro studies focusing on the function of miR-1246 in cancer.

\section{ANIMAL STUDIES}

Most of animal studies have indicated an oncogenic role for miR1246 , since its silencing has led to reduction of tumor size and attenuation of tumor growth (Table 2). Moreover, expression of miR-1246 has been found to be elevated in the plasma exosomes of patient-originated orthotopic xenograft animals compared to control animals (Hannafon et al., 2016). However, in prostate cancer, miR-1246 up-regulation has significantly inhibited tumor growth in the xenograft models, suggesting its tumor suppressive role. Moreover, in miR-1246 overexpressing xenograft models, exosomal levels of this miRNA has been reduced. Taken together, miR-1246 has been identified as a tumor suppressor miRNA being selectively packaged in prostate cancer exosomes, resulting in its high abundance in serum yet low concentrations inside the cells (Bhagirath et al., 2018). In the xenograft model of leukemia, miR-1246-containing extracellular vesicles have been shown to confer quiescence on residual hematopoietic stem cells (Abdelhamed et al., 2019).

\section{CLINICAL STUDIES}

Serum levels of miR-1246 have been found to be higher in the sera of colorectal cancer patients compared to healthy subjects (Salah et al., 2020). Similarly, miR-1246 has been found as the most up-regulated miRNA in the sera of patients with lung cancer (Yang et al., 2019). Levels of miR-1246 have been found to be higher in laryngeal squamous cell carcinoma tissues and plasma small extracellular vesicles. This miRNA has been more enriched in small extracellular vesicles instead of being in soluble form (Sakha et al., 2016). Almost all studies in clinical settings have reported up-regulation of miR-1246 in neoplastic tissues and sera of patients compared with controls (Table 3).

However, Yang et al. have shown down-regulation of miR1246 in cervical cancer tissues compared with normal controls. Notably, down-regulation of miR-1246 has been inversely correlated with clinical stage and HPV16 E6 infection. Yet, its levels have not been correlated with age, tumor diameters, invasion deepness, lymph node involvement, or vascular invasion (Yang et al., 2015).

Table 3 Results of studies that reported dysregulation of miR1246 or other genes that interact with miR-1246 in clinical samples (OS: Overall survival, DFS: disease-free survival, TNM: tumor-node-metastasis, ANCTs: adjacent noncancerous tissues, FN: Fusobacterium nucleatum, CD44v6: a CSC population with increased resistance to chemotherapeutic agents, NMRD: non-malignant respiratory diseases, NSCLC: non-small cell lung cancer, PTGs: potential target genes, LUAD: lung adenocarcinoma, ESCC: esophageal squamous cell carcinoma, miR-1246real and miR-1246pred: real and predicted miR-1246 expression levels, BPH: benign prostate hyperplasia, EFS: event-free survival, PFS: progression-free survival, LC: liver cirrhosis, CH: chronic hepatitis, HC: healthy controls, UICC: Union for International Cancer Control, GBM: glioblastoma, LGG: low-grade glioma, PDAC: pancreatic ductal 
TABLE 3 | Results of studies that reported dysregulation of miR-1246 or other genes that interact with miR-1246 in clinical samples.

\begin{tabular}{|c|c|c|c|c|c|c|c|}
\hline Tumor type & Samples & $\begin{array}{l}\text { Expression of miR- } \\
1246 \text { or other genes } \\
\text { (tumor vs. normal) }\end{array}$ & $\begin{array}{c}\text { Kaplan-Meier } \\
\text { analysis (impact of } \\
\text { miR-1246 } \\
\text { dysregulation or } \\
\text { other genes } \\
\text { dysregulation) }\end{array}$ & $\begin{array}{l}\text { Univariate/ } \\
\text { Multivariate cox } \\
\text { regression }\end{array}$ & $\begin{array}{l}\text { Association of } \\
\text { expression of miR- } \\
1246 \text { or expression of } \\
\text { other genes with } \\
\text { clinicopathologic } \\
\text { characteristics }\end{array}$ & $\begin{array}{l}\text { Method for assessment } \\
\text { of miR-1246 expression }\end{array}$ & References \\
\hline \multirow[t]{11}{*}{$\begin{array}{l}\text { Colorectal } \\
\text { cancer (CRC) }\end{array}$} & $\begin{array}{l}60 \text { pairs of CRC } \\
\text { tissues and ANCTs }\end{array}$ & $\begin{array}{l}\text { Up-regulation of m6A } \\
\text { Up-regulation of } \\
\text { METTL3 }\end{array}$ & - & - & $\begin{array}{l}\text { lymph node invasion, and } \\
\text { distant metastasis }\end{array}$ & SYBR Premix Ex Taq Kit & $\begin{array}{l}\text { Peng et al. } \\
\text { (2019) }\end{array}$ \\
\hline & $\begin{array}{l}\text { GEO database: } \\
\text { GSE17536 }\end{array}$ & $\begin{array}{l}\text { Up-regulation of } \\
\text { METTL3 }\end{array}$ & Lower OS & - & - & & \\
\hline & $\begin{array}{l}\text { Serum samples from } \\
82 \text { patients and } \\
\text { blood samples from } \\
102 \text { healthy controls }\end{array}$ & $\begin{array}{l}\text { Up-regulation of miR- } \\
1246\end{array}$ & - & - & - & $\begin{array}{l}\text { Mir-X miRNA RT-qPCR TB } \\
\text { Green Kit }\end{array}$ & $\begin{array}{l}\text { Guo et al. } \\
(2021)\end{array}$ \\
\hline & $\begin{array}{l}40 \text { CRC Patients } \\
\text { and } 40 \text { healthy } \\
\text { controls }\end{array}$ & $\begin{array}{l}\text { Up-regulation of } \\
\text { exosomal miR-1246 }\end{array}$ & - & - & - & & \\
\hline & 82 fecal samples & $\begin{array}{l}\text { Up-regulation of miR- } \\
1246\end{array}$ & - & - & Abundance of Fn & & \\
\hline & $\begin{array}{l}\text { sera of } 37 \mathrm{CRC} \\
\text { patients and } 30 \\
\text { healthy controls }\end{array}$ & $\begin{array}{l}\text { Up-regulation of miR- } \\
1246\end{array}$ & - & - & - & $\begin{array}{l}\text { miScript syber green PCR kit } \\
\text { (Qiagen) }\end{array}$ & $\begin{array}{l}\text { Salah et al. } \\
(2020)\end{array}$ \\
\hline & $\begin{array}{l}10 \text { pairs of CRC } \\
\text { tissues and ANCTs }\end{array}$ & $\begin{array}{l}\text { Up-regulation of miR- } \\
1246\end{array}$ & - & - & - & $\begin{array}{l}\text { mirVana }{ }^{T M} \text { qRT-PCR } \\
\text { microRNA detection kit }\end{array}$ & $\begin{array}{l}\text { Wang et al. } \\
(2016)\end{array}$ \\
\hline & $\begin{array}{l}\text { Serum samples from } \\
43 \text { CRC patients }\end{array}$ & $\begin{array}{l}\text { Up-regulation of miR- } \\
1246 \text { in } \\
\text { chemoresistant } \\
\text { patients }\end{array}$ & - & - & - & TaqMan miRNA Assay & Jin et al. (2019) \\
\hline & 26 CRC patients & $\begin{array}{l}\text { Up-regulation of miR- } \\
1246 \text { (lower in post- } \\
\text { treatment sera) }\end{array}$ & - & - & - & Taqman miRNA Assay & $\begin{array}{l}\text { Handa et al. } \\
(2021)\end{array}$ \\
\hline & $\begin{array}{l}181 \text { pairs of CRC } \\
\text { tissues and ANCTs }\end{array}$ & $\begin{array}{l}\text { Up-regulation of miR- } \\
1246\end{array}$ & - & - & CD44v6 status & SYBR Green & $\begin{array}{l}\text { Toden et al. } \\
\text { (2019) }\end{array}$ \\
\hline & $\begin{array}{l}150 \text { pairs of CRC } \\
\text { tissues and ANCTs }\end{array}$ & $\begin{array}{l}\text { Up-regulation of miR- } \\
1246\end{array}$ & worse OS and DFS & $\begin{array}{l}\text { miR-1246 was found } \\
\text { to be an independent } \\
\text { prognostic factor for } \\
\text { OS and DFS }\end{array}$ & stage IV & & \\
\hline $\begin{array}{l}\text { Colorectal cancer } \\
\text { (CRC) and } \\
\text { Colorectal } \\
\text { adenomas (CRA) }\end{array}$ & $\begin{array}{l}6 \mathrm{CRC} \text { and } 8 \mathrm{CRA} \\
\text { patients }\end{array}$ & $\begin{array}{l}\text { Up-regulation of miR- } \\
1246 \text { in both cellular } \\
\text { compartments and } \\
\text { exosomes (higher in } \\
\text { CRC-derived } \\
\text { organoids than CRA- } \\
\text { derived organoids) }\end{array}$ & - & - & - & $\begin{array}{l}\text { TaqMan }{ }^{\mathrm{TM}} \text { Advanced } \\
\text { miRNA assays }\end{array}$ & $\begin{array}{l}\text { Nagai et al. } \\
(2021)\end{array}$ \\
\hline \multirow[t]{3}{*}{ Colon cancer } & $\begin{array}{l}88 \text { primary CRC } \\
\text { patients and } 11 \\
\text { healthy controls }\end{array}$ & $\begin{array}{l}\text { Up-regulation of miR- } \\
1246\end{array}$ & - & - & - & TaqMan microRNA kits & $\begin{array}{l}\text { Ogata-Kawata } \\
\text { et al. (2014) }\end{array}$ \\
\hline & $\begin{array}{l}\text { Serum from } 29 \text { of } \\
\text { the patients after } \\
\text { surgical resection }\end{array}$ & $\begin{array}{l}\text { Down-regulation of } \\
\text { miR-1246 }\end{array}$ & - & - & - & & \\
\hline & $\begin{array}{l}13 \text { CRC patients } \\
\text { and } 8 \text { healthy } \\
\text { controls }\end{array}$ & $\begin{array}{l}\text { Up-regulation of miR- } \\
1246\end{array}$ & - & - & - & & \\
\hline \multirow[t]{3}{*}{ Lung cancer } & $\begin{array}{l}\text { serum from } 11 \text { lung } \\
\text { cancer patients and } \\
5 \text { healthy control }\end{array}$ & $\begin{array}{l}\text { Up-regulation of miR- } \\
1246\end{array}$ & - & - & metastasis & SYBR Green & $\begin{array}{l}\text { Yang et al. } \\
(2019)\end{array}$ \\
\hline & $\begin{array}{l}105 \mathrm{NSCLC} \\
\text { patients, } 50 \mathrm{NMRD} \\
\text { patients, and } 50 \\
\text { healthy controls }\end{array}$ & $\begin{array}{l}\text { Up-regulation of miR- } \\
1246 \text { in NSCLC } \\
\text { patients than in } \\
\text { patients with NMRD } \\
\text { and healthy controls }\end{array}$ & Worse OS and DFS & $\begin{array}{l}\text { Serum exosomal } \\
\text { miR-1246, TNM } \\
\text { stage, and lymph } \\
\text { node metastasis were } \\
\text { found as independent } \\
\text { prognostic factors } \\
\text { for OS. }\end{array}$ & $\begin{array}{l}\text { advanced clinical stage } \\
\text { and with lymph node } \\
\text { metastasis }\end{array}$ & $\begin{array}{l}\text { miScript SYBR-Green } \\
\text { PCR Kit }\end{array}$ & $\begin{array}{l}\text { Huang and Qu } \\
(2020)\end{array}$ \\
\hline & $\begin{array}{l}\text { GEO database: } \\
\text { GSE137140 and } \\
\text { GSE69732 }\end{array}$ & $\begin{array}{l}\text { Up-regulation of miR- } \\
1246\end{array}$ & $\begin{array}{l}\text { High expression of } \\
\text { UBE2C, UCHL1, } \\
\text { TRAIP, TNNT1, } \\
\text { TNNI3, RAC3 (PTGs } \\
\text { of cmiRNA-1246) = } \\
\text { poor OS } \\
\text { High expressions of } \\
\text { PITX2, NRAS, } \\
\text { ENFA4, DNAJA3, }\end{array}$ & - & - & - & $\begin{array}{l}\text { Huang et al. } \\
\text { (2020c) }\end{array}$ \\
\hline
\end{tabular}


TABLE 3 | (Continued) Results of studies that reported dysregulation of miR-1246 or other genes that interact with miR-1246 in clinical samples.

\begin{tabular}{|c|c|c|c|c|c|c|c|}
\hline Tumor type & Samples & $\begin{array}{l}\text { Expression of miR- } \\
1246 \text { or other genes } \\
\text { (tumor vs. normal) }\end{array}$ & $\begin{array}{c}\text { Kaplan-Meier } \\
\text { analysis (impact of } \\
\text { miR-1246 } \\
\text { dysregulation or } \\
\text { other genes } \\
\text { dysregulation) }\end{array}$ & $\begin{array}{l}\text { Univariate/ } \\
\text { Multivariate cox } \\
\text { regression }\end{array}$ & $\begin{array}{l}\text { Association of } \\
\text { expression of miR- } \\
1246 \text { or expression of } \\
\text { other genes with } \\
\text { clinicopathologic } \\
\text { characteristics }\end{array}$ & $\begin{array}{l}\text { Method for assessment } \\
\text { of miR-1246 expression }\end{array}$ & References \\
\hline & & & $\begin{array}{l}\text { TBCE, and } \\
\text { TGIF1(PTGs of } \\
\text { cmiRNA-1246) = } \\
\text { longer OS in LUAD } \\
\text { patients }\end{array}$ & & & & \\
\hline \multirow[t]{3}{*}{ Lung cancer } & $\begin{array}{l}86 \text { pairs of NSCLC } \\
\text { tissues and ANCTs }\end{array}$ & $\begin{array}{l}\text { Up-regulation of } \\
\text { METTL3 (that } \\
\text { upregulates miR- } \\
\text { 1246) }\end{array}$ & - & - & $\begin{array}{l}\text { Lymph node metastasis, } \\
\text { tumor size, and TNM } \\
\text { stage }\end{array}$ & TaqMan MicroRNA Assays & $\begin{array}{l}\text { Huang et al. } \\
(2021)\end{array}$ \\
\hline & $\begin{array}{l}86 \text { pairs of NSCLC } \\
\text { tissues and ANCTs }\end{array}$ & $\begin{array}{l}\text { Up-regulation of m6A } \\
\text { and Up-regulation of } \\
\text { miR-1246 }\end{array}$ & - & - & - & & \\
\hline & $\begin{array}{l}52 \text { NSCLC patients } \\
\text { and } 45 \text { healthy } \\
\text { controls }\end{array}$ & $\begin{array}{l}\text { Up-regulation of miR- } \\
1246\end{array}$ & - & - & - & $\begin{array}{l}\text { QIAGEN SYBR green } \\
\text { Master Mix }\end{array}$ & $\begin{array}{l}\text { Zheng et al. } \\
\text { (2021) }\end{array}$ \\
\hline \multirow[t]{3}{*}{ Cervical cancer } & $\begin{array}{l}68 \text { cervical cancer } \\
\text { patients and } 52 \\
\text { healthy controls }\end{array}$ & $\begin{array}{l}\text { Down-regulation of } \\
\text { miR-1246 }\end{array}$ & - & - & $\begin{array}{l}\text { Advanced clinical stage, } \\
\text { invasive cervical wall N1/ } \\
\text { 2, HPV positivity }\end{array}$ & $\begin{array}{l}\text { Stem-loop primers using } \\
\text { SYBR }^{\circledR} \text { Premix Ex Taq } \\
\text { ॥ kit }\end{array}$ & $\begin{array}{l}\text { Yang et al. } \\
(2015)\end{array}$ \\
\hline & $\begin{array}{l}18 \text { pairs of cervical } \\
\text { cancer tissues and } \\
\text { ANCTs }\end{array}$ & $\begin{array}{l}\text { Down-regulation of } \\
\text { miR-1246 }\end{array}$ & - & - & - & & \\
\hline & $\begin{array}{l}26 \text { cervical cancer } \\
\text { patients and } 16 \\
\text { healthy controls }\end{array}$ & $\begin{array}{l}\text { Up-regulation of miR- } \\
1246\end{array}$ & - & - & - & $\begin{array}{l}\text { TaqMan miRNA RT-Kit with } \\
\text { stem-loop RT-primer }\end{array}$ & $\begin{array}{l}\text { Nagamitsu et al. } \\
(2016)\end{array}$ \\
\hline \multirow[t]{8}{*}{$\begin{array}{l}\text { Esophageal } \\
\text { cancer }\end{array}$} & $\begin{array}{l}\text { Serum from } 55 \\
\text { ESCC patients and } \\
39 \text { healthy controls }\end{array}$ & $\begin{array}{l}\text { Up-regulation of miR- } \\
1246\end{array}$ & - & - & - & $\begin{array}{l}\text { miScript SYBR }{ }^{\circledR} \text {-Green } \\
\text { PCR Kit (Qiagen) }\end{array}$ & $\begin{array}{l}\text { Hoshino et al. } \\
\text { (2020a) }\end{array}$ \\
\hline & $\begin{array}{l}\text { Serum from } 101 \\
\text { ESCC patients and } \\
34 \text { healthy controls }\end{array}$ & $\begin{array}{l}\text { Up-regulation of miR- } \\
1246\end{array}$ & $\begin{array}{l}\text { Worse } 5 \text {-years OS } \\
\text { and DFS }\end{array}$ & - & $\begin{array}{l}\text { Tumor depth, positive } \\
\text { lymph node metastasis, } \\
\text { stage, and survival of } \\
\text { patients }\end{array}$ & & \\
\hline & $\begin{array}{l}101 \text { ESCC patients } \\
\text { and } 35 \text { healthy } \\
\text { controls }\end{array}$ & $\begin{array}{l}\text { Up-regulation of miR- } \\
1246\end{array}$ & - & $\begin{array}{l}\text { miR-1246real was } \\
\text { found to be an } \\
\text { independent factor for } \\
\mathrm{N} \text { stage and miR- } \\
1246 \text { real, and miR- } \\
1246 \text { pred was found } \\
\text { to be an independent } \\
\text { factor for } \mathrm{N} \text { stage and } \\
\mathrm{miR}-1246 \text { pred }\end{array}$ & - & $\begin{array}{l}\text { miScript SYBR }{ }^{\circledR} \text {-Green } \\
\text { PCR Kit (Qiagen }\end{array}$ & $\begin{array}{l}\text { Hoshino et al. } \\
\text { (2020b) }\end{array}$ \\
\hline & $\begin{array}{l}\text { Serum from } 101 \\
\text { ESCC patients and } \\
46 \text { healthy controls }\end{array}$ & $\begin{array}{l}\text { Up-regulation of miR- } \\
1246\end{array}$ & lower 2-years OS & $\begin{array}{l}\text { Expression of miR- } \\
1246 \text { was the } \\
\text { strongest } \\
\text { independent risk } \\
\text { factor for a poor } \\
\text { survival with a hazard } \\
\text { ratio of } 4.032\end{array}$ & $\begin{array}{l}\text { T3-4, lymph node } \\
\text { metastasis, distant } \\
\text { metastasis, stage III-IV }\end{array}$ & TaqMan MicroRNA Assays & $\begin{array}{l}\text { Takeshita et al. } \\
\text { (2013) }\end{array}$ \\
\hline & $\begin{array}{l}22 \text { pairs of ESCC } \\
\text { tissues and ANCTs }\end{array}$ & $\begin{array}{l}\text { No significant } \\
\text { differences }\end{array}$ & - & - & - & & \\
\hline & 32 lymph nodes & $\begin{array}{l}\text { Higher in proximal } \\
\text { lymph nodes than } \\
\text { abdominal lymph } \\
\text { nodes, thoracic lymph } \\
\text { nodes, and cervical } \\
\text { lymph nodes }\end{array}$ & - & - & - & & \\
\hline & $\begin{array}{l}\text { Serum from } 72 \\
\text { ESCC patients and } \\
50 \text { healthy controls }\end{array}$ & $\begin{array}{l}\text { Up-regulation of miR- } \\
1246\end{array}$ & worse OS & - & $\begin{array}{l}\text { Tumor invasion and } \\
\text { positive lymph node } \\
\text { metastasis, albeit } \\
\text { insignificantly }\end{array}$ & $\begin{array}{l}\text { miScript SYBR }{ }^{\circledR} \text { Green PCR } \\
\text { kit (Qiagen) }\end{array}$ & $\begin{array}{l}\text { Hoshino et al. } \\
(2021)\end{array}$ \\
\hline & $\begin{array}{l}\text { Urine from } 72 \text { ESCC } \\
\text { patients and } 50 \\
\text { healthy controls }\end{array}$ & $\begin{array}{l}\text { Up-regulation of miR- } \\
1246\end{array}$ & - & - & - & - & \\
\hline \multirow[t]{2}{*}{$\begin{array}{l}\text { Prostate } \\
\text { cancer (PCa) }\end{array}$} & $\begin{array}{l}\text { Serum from } 6 \mathrm{PCa} \\
\text { patients, } 3 \mathrm{BPH} \\
\text { patients and } 3 \\
\text { healthy controls }\end{array}$ & $\begin{array}{l}\text { Up-regulation of miR- } \\
1246 \text { in PCa than BPH } \\
\text { and healthy controls }\end{array}$ & - & - & $\begin{array}{l}\text { Advancing PCa stage, } \\
\text { lymph node metastasis }\end{array}$ & TaqMan MicroRNA Assays & $\begin{array}{l}\text { Bhagirath et al. } \\
(2018)\end{array}$ \\
\hline & & & - & - & & \multicolumn{2}{|c|}{ (Continued on following page) } \\
\hline
\end{tabular}


TABLE 3 | (Continued) Results of studies that reported dysregulation of miR-1246 or other genes that interact with miR-1246 in clinical samples.

\begin{tabular}{|c|c|c|c|c|c|c|c|}
\hline Tumor type & Samples & $\begin{array}{l}\text { Expression of miR- } \\
1246 \text { or other genes } \\
\text { (tumor vs. normal) }\end{array}$ & $\begin{array}{c}\text { Kaplan-Meier } \\
\text { analysis (impact of } \\
\text { miR-1246 } \\
\text { dysregulation or } \\
\text { other genes } \\
\text { dysregulation) }\end{array}$ & $\begin{array}{l}\text { Univariate/ } \\
\text { Multivariate cox } \\
\text { regression }\end{array}$ & $\begin{array}{l}\text { Association of } \\
\text { expression of miR- } \\
1246 \text { or expression of } \\
\text { other genes with } \\
\text { clinicopathologic } \\
\text { characteristics }\end{array}$ & $\begin{array}{l}\text { Method for assessment } \\
\text { of miR-1246 expression }\end{array}$ & References \\
\hline & $\begin{array}{l}\text { Serum form } 44 \mathrm{PCa} \\
\text { patients, } 4 \mathrm{BPH} \\
\text { patients and } 8 \\
\text { healthy controls }\end{array}$ & $\begin{array}{l}\text { Up-regulation of ex- } \\
\text { miR-1246 in PCa than } \\
\text { BPH and healthy } \\
\text { controls }\end{array}$ & & & $\begin{array}{l}\text { Advancing PCa stage, } \\
\text { lymph node metastasis }\end{array}$ & & \\
\hline & $\begin{array}{l}36 \text { pairs of } \mathrm{PCa} \\
\text { tissues and } \mathrm{ANCTs}\end{array}$ & $\begin{array}{l}\text { Down-regulation of } \\
\text { miR-1246 }\end{array}$ & - & - & - & & \\
\hline \multirow[t]{4}{*}{ Breast cancer } & $\begin{array}{l}\text { Circulating } \\
\text { exosomal miRNA } \\
\text { from } 4 \text { trastuzumab- } \\
\text { resistant and } 4 \\
\text { sensitive patients }\end{array}$ & $\begin{array}{l}\text { Up-regulation of miR- } \\
1246 \text { in trastuzumab- } \\
\text { resistant HER2- } \\
\text { positive breast cancer } \\
\text { patients }\end{array}$ & poorer EFS & $\begin{array}{l}\text { Expression of miR- } \\
1246 \text { strongly } \\
\text { showed poor EFS for } \\
\text { early-stage patients, } \\
\text { and poor PFS for } \\
\text { metastatic patients }\end{array}$ & - & $\begin{array}{l}\text { miScript SYBR Green PCR } \\
\text { Kit (Qiagen) }\end{array}$ & $\begin{array}{l}\text { Zhang et al. } \\
(2020)\end{array}$ \\
\hline & $\begin{array}{l}\text { Plasma from } 16 \\
\text { breast cancer } \\
\text { patients and } 16 \\
\text { healthy controls }\end{array}$ & $\begin{array}{l}\text { Up-regulation of miR- } \\
1246 \text { in plasma } \\
\text { exosomes }\end{array}$ & - & - & - & $\begin{array}{l}\text { Stem-loop primer using } \\
\text { TaqMan microRNA Reverse } \\
\text { Transcription Kit }\end{array}$ & $\begin{array}{l}\text { Hannafon et al. } \\
(2016)\end{array}$ \\
\hline & $\begin{array}{l}\text { Serum from } 56 \\
\text { breast cancer } \\
\text { patients and } 19 \\
\text { healthy controls }\end{array}$ & $\begin{array}{l}\text { Up-regulation of miR- } \\
1246\end{array}$ & - & - & - & Taqman assay & Li et al. (2017) \\
\hline & $\begin{array}{l}11 \text { studies with } 921 \\
\text { breast cancer } \\
\text { patients }\end{array}$ & $\begin{array}{l}\text { Up-regulation of miR- } \\
1246\end{array}$ & - & - & - & - & $\begin{array}{l}\text { Wang et al. } \\
\text { (2018a) }\end{array}$ \\
\hline \multirow[t]{3}{*}{ Breast cancer } & $\begin{array}{l}\text { Serum from } 100 \\
\text { breast cancer } \\
\text { patients and } 40 \\
\text { healthy controls }\end{array}$ & $\begin{array}{l}\text { Up-regulation of miR- } \\
1246\end{array}$ & - & - & - & $\begin{array}{l}\text { miScript SYBR Green PCR } \\
\text { kit (Qiagen } \mathrm{GmbH} \text { ) }\end{array}$ & Fu et al. (2016) \\
\hline & $\begin{array}{l}\text { GEO database: } \\
\text { (GSE73002) }(1,288 \\
\text { BC patients and } \\
2,686 \text { healthy } \\
\text { controls) }\end{array}$ & $\begin{array}{l}\text { Up-regulation of miR- } \\
1246\end{array}$ & - & - & - & - & Cui et al. (2018) \\
\hline & $\begin{array}{l}\text { GEO database: } \\
\text { (GSE73002) (429 } \\
\text { BC patients and } 895 \\
\text { healthy controls.) }\end{array}$ & $\begin{array}{l}\text { Up-regulation of miR- } \\
1246\end{array}$ & - & - & - & & \\
\hline \multirow[t]{9}{*}{$\begin{array}{l}\text { Hepatocellular } \\
\text { carcinoma (HCC) }\end{array}$} & $\begin{array}{l}\text { Serum from } 33 \\
\text { primary HCC } \\
\text { patients, } 22 \\
\text { metastatic liver } \\
\text { tumor patients, } 30 \\
\text { healthy controls }\end{array}$ & $\begin{array}{l}\text { Up-regulation of miR- } \\
1246 \text { in metastatic } \\
\text { liver tumors }\end{array}$ & - & - & $\begin{array}{l}\text { Females, patients } \\
\leq 60 \text { years old, and } \\
\text { patients with cirrhosis and } \\
\text { low level of serum AFP }\end{array}$ & $\begin{array}{l}\text { miScript SYBER Green PCR } \\
\text { kit (Qiagen) }\end{array}$ & $\begin{array}{l}\text { Ahmed et al. } \\
(2019)\end{array}$ \\
\hline & $\begin{array}{l}7 \text { HCC patients, } 21 \\
\text { cirrhosis patients } \\
\text { and } 14 \text { healthy } \\
\text { controls }\end{array}$ & $\begin{array}{l}\text { Up-regulation of miR- } \\
1246\end{array}$ & - & - & - & $\begin{array}{l}\text { QX200 EvaGreen ddPCR } \\
\text { protocol }\end{array}$ & $\begin{array}{l}\text { Moshiri et al. } \\
(2018)\end{array}$ \\
\hline & $\begin{array}{l}\text { Plasmas from } 9 \\
\text { HCC and } 6 \text { cirrhotic } \\
\text { patients }\end{array}$ & $\begin{array}{l}\text { Up-regulation of miR- } \\
1246\end{array}$ & - & - & - & & \\
\hline & $\begin{array}{l}\text { Plasmas from } 22 \\
\text { HCC patients and } \\
11 \text { healthy controls }\end{array}$ & $\begin{array}{l}\text { Up-regulation of miR- } \\
1246\end{array}$ & - & - & - & & \\
\hline & $\begin{array}{l}\text { Plasmas from } 24 \\
\text { HCC and } 14 \\
\text { cirrhotic patients }\end{array}$ & $\begin{array}{l}\text { Up-regulation of miR- } \\
1246\end{array}$ & - & - & - & & \\
\hline & $\begin{array}{l}\text { Serum from } 50 \mathrm{HCC} \\
\text { patients and } 50 \\
\text { healthy controls }\end{array}$ & $\begin{array}{l}\text { Up-regulation of miR- } \\
1246\end{array}$ & shorter OS & - & - & $\begin{array}{l}\text { miScript SYBR-Green PCR } \\
\text { Kit (Qiagen } \mathrm{GmbH} \text { ) }\end{array}$ & $\begin{array}{l}\text { Chen et al. } \\
\text { (2021b) }\end{array}$ \\
\hline & $\begin{array}{l}50 \text { pairs of HCC } \\
\text { tissues and ANCTs }\end{array}$ & $\begin{array}{l}\text { Up-regulation of miR- } \\
1246\end{array}$ & - & - & $\begin{array}{l}\text { TNM staging, } \\
\text { differentiation, and } \\
\text { metastasis }\end{array}$ & & \\
\hline & $\begin{array}{l}31 \text { pairs of HCC } \\
\text { tissues and ANCTs }\end{array}$ & $\begin{array}{l}\text { Up-regulation of miR- } \\
1246\end{array}$ & - & - & - & $\begin{array}{l}\text { An Agilent oligonucleotide } \\
\text { microarray system (Agilent } \\
\text { Gene Spring GX11.51, } \\
\text { Agilent Technologies) }\end{array}$ & $\begin{array}{l}\text { Huang et al. } \\
\text { (2020a) }\end{array}$ \\
\hline & $\begin{array}{l}\text { Serum from } 121 \\
\text { HCC patients, } 48\end{array}$ & $\begin{array}{l}\text { Up-regulation of miR- } \\
1246 \text { in HCC }\end{array}$ & shorter OS and DFS & $\begin{array}{l}\text { Serum miR-1246, } \\
\text { Albumin, AFP-L3, }\end{array}$ & $\begin{array}{l}\text { UICC-TNM classification, } \\
\text { tumor differentiation, and }\end{array}$ & $\begin{array}{l}\text { TaqMan Advanced miRNA } \\
\text { Assays }\end{array}$ & $\begin{array}{l}\text { Chuma et al. } \\
(2019)\end{array}$ \\
\hline
\end{tabular}


TABLE 3 | (Continued) Results of studies that reported dysregulation of miR-1246 or other genes that interact with miR-1246 in clinical samples.

\begin{tabular}{|c|c|c|c|c|c|c|c|}
\hline Tumor type & Samples & $\begin{array}{l}\text { Expression of miR- } \\
1246 \text { or other genes } \\
\text { (tumor vs. normal) }\end{array}$ & $\begin{array}{c}\text { Kaplan-Meier } \\
\text { analysis (impact of } \\
\text { miR-1246 } \\
\text { dysregulation or } \\
\text { other genes } \\
\text { dysregulation) }\end{array}$ & $\begin{array}{l}\text { Univariate/ } \\
\text { Multivariate cox } \\
\text { regression }\end{array}$ & $\begin{array}{l}\text { Association of } \\
\text { expression of miR- } \\
1246 \text { or expression of } \\
\text { other genes with } \\
\text { clinicopathologic } \\
\text { characteristics }\end{array}$ & $\begin{array}{l}\text { Method for assessment } \\
\text { of miR-1246 expression }\end{array}$ & References \\
\hline & $\begin{array}{l}\text { CH patients, } 25 \text { LC } \\
\text { patients and } 15 \\
\text { healthy controls }\end{array}$ & $\begin{array}{l}\text { compared to } \mathrm{CH} \text {, } \\
\mathrm{LC}, \mathrm{HC}\end{array}$ & & $\begin{array}{l}\text { tumor differentiation, } \\
\text { and were } \\
\text { independently } \\
\text { correlated with poor } \\
\text { prognosis }\end{array}$ & $\begin{array}{l}\text { pathological portal vein } \\
\text { invasion }\end{array}$ & & \\
\hline & $\begin{array}{l}38 \text { liver cancer } \\
\text { patients }\end{array}$ & $\begin{array}{l}\text { Up-regulation of miR- } \\
1246\end{array}$ & shorter DFS & - & - & $\begin{array}{l}\text { miScript SYBR Green PCR } \\
\text { kit (Qiagen) }\end{array}$ & Sun et al. (2014) \\
\hline & $\begin{array}{l}28 \text { pairs of HCC } \\
\text { tissues and ANCTs }\end{array}$ & $\begin{array}{l}\text { Expression of miR- } \\
1246 \text { was consistent } \\
\text { with p53 levels }\end{array}$ & - & - & - & SYBR PremixEx Taq ${ }^{\mathrm{TM}}$ & $\begin{array}{l}\text { Zhang et al. } \\
\text { (2015) }\end{array}$ \\
\hline & $\begin{array}{l}62 \text { HCC patients } \\
\text { received liver } \\
\text { transplantation }\end{array}$ & $\begin{array}{l}\text { Up-regulation of miR- } \\
1246 \text { in HCC } \\
\text { recipients with HCC } \\
\text { recurrence after liver } \\
\text { transplantation than } \\
\text { those without tumor } \\
\text { recurrence }\end{array}$ & $\begin{array}{l}\text { Poor OS and DFS } \\
\text { after liver } \\
\text { transplantation }\end{array}$ & $\begin{array}{l}\text { Early-phase } \\
\text { circulating miR-1246 } \\
\text { was found to be } \\
\text { significant predictor } \\
\text { for predicting OS and } \\
\text { DFS of HCC } \\
\text { recipients }\end{array}$ & $\begin{array}{l}\text { The serum AST level from } \\
\text { day } 0 \text { to day } 3 \text {, serum ALT } \\
\text { level from day } 0 \text { to day } 6 \\
\text { after liver transplantation, } \\
\text { and expression of TNF-a }\end{array}$ & TaqMan MicroRNA Assays & $\mathrm{Ng}$ et al. (2016) \\
\hline & $\begin{array}{l}114 \text { pairs of HCC } \\
\text { tissues and ANCTs }\end{array}$ & $\begin{array}{l}\text { Up-regulation of miR- } \\
1246\end{array}$ & Worse OS and DFS & $\begin{array}{l}\text { miR-1246 was an } \\
\text { independent } \\
\text { prognostic factor for } \\
\text { both OS and DFS. }\end{array}$ & $\begin{array}{l}\text { Serum alpha fetoprotein } \\
\text { (AFP) level }\end{array}$ & - & $\begin{array}{l}\text { Chai et al. } \\
(2016)\end{array}$ \\
\hline & $\begin{array}{l}5 \mathrm{LC} \text { and } 5 \mathrm{HCC} \\
\text { patients }\end{array}$ & $\begin{array}{l}\text { Higher in HCC than } \\
\text { in LC }\end{array}$ & - & - & - & $\begin{array}{l}\text { TaqMan microRNA Reverse } \\
\text { Transcription Kit }\end{array}$ & $\begin{array}{l}\text { Wang et al. } \\
\text { (2018b) }\end{array}$ \\
\hline & $\begin{array}{l}10 \mathrm{CH}, 13 \mathrm{LC}, 18 \\
\text { HCC patients and } \\
14 \text { healthy controls }\end{array}$ & $\begin{array}{l}\text { Higher in HCC than in } \\
\mathrm{LC} \text { and } \mathrm{CH} \text { groups, } \\
\text { not different from NC } \\
\text { group }\end{array}$ & - & - & - & & \\
\hline & $\begin{array}{l}40 \mathrm{CH}, 40 \mathrm{LC}, 50 \\
\mathrm{HCC} \text { patients and } \\
50 \text { healthy controls }\end{array}$ & $\begin{array}{l}\text { Up-regulation of miR- } \\
1246 \text { in HCC than in } \\
\text { LC and NC groups }\end{array}$ & - & - & - & & \\
\hline \multirow{4}{*}{$\begin{array}{l}\text { Oral squamous } \\
\text { cell carcinoma } \\
\text { (OSCC) }\end{array}$} & $\begin{array}{l}30 \text { pairs of OSCC } \\
\text { tissues and ANCTs }\end{array}$ & $\begin{array}{l}\text { Up-regulation of miR- } \\
1246\end{array}$ & poor OS & - & $\begin{array}{l}\text { T category, stage, and } \\
\text { lymph node metastasis }\end{array}$ & TaqMan miRNA assays & Lin et al. (2018) \\
\hline & $\begin{array}{l}106 \text { pairs of OSCC } \\
\text { tissues and ANCTs }\end{array}$ & $\begin{array}{l}\text { Up-regulation of miR- } \\
1246\end{array}$ & poor OS & $\begin{array}{l}\text { miR-1246 } \\
\text { expression, tumor } \\
\text { grade and TNM stage } \\
\text { were independent } \\
\text { prognostic factors for } \\
\text { OSCC. }\end{array}$ & $\begin{array}{l}\text { TNM stage, nodal status, } \\
\text { and tumor grade }\end{array}$ & $\begin{array}{l}\text { SYBR PrimeScript miRNA } \\
\text { RT-PCR kit }\end{array}$ & $\begin{array}{l}\text { Liao et al. } \\
\text { (2015) }\end{array}$ \\
\hline & $\begin{array}{l}\text { Plasma from } 10 \\
\text { advanced OSCC } \\
\text { patients and } 10 \\
\text { healthy controls }\end{array}$ & $\begin{array}{l}\text { Up-regulation of miR- } \\
1246\end{array}$ & - & - & - & $\begin{array}{l}\text { miScript SYBR Green PCR } \\
\text { kit (QIAGEN) }\end{array}$ & $\begin{array}{l}\text { Nakashima } \\
\text { et al. (2019) }\end{array}$ \\
\hline & $\begin{array}{l}55 \text { advanced OSCC } \\
\text { patients }\end{array}$ & $\begin{array}{l}\text { Up-regulation of miR- } \\
1246\end{array}$ & - & - & Tumor stage & & \\
\hline \multirow[t]{3}{*}{$\begin{array}{l}\text { Laryngeal } \\
\text { squamous cell } \\
\text { carcinoma (LSCC) }\end{array}$} & $\begin{array}{l}\text { Plasma from } 61 \\
\text { LSCC patients, } 26 \\
\text { healthy controls }\end{array}$ & $\begin{array}{l}\text { Up-regulation of miR- } \\
1246\end{array}$ & poor Os & - & - & $\begin{array}{l}\text { miScript SYBR Green PCR } \\
\text { Kit (QIAGEN) }\end{array}$ & $\begin{array}{l}\text { Huang et al. } \\
\text { (2020b) }\end{array}$ \\
\hline & $\begin{array}{l}61 \text { pairs of LSCC } \\
\text { tissues and ANCTs }\end{array}$ & $\begin{array}{l}\text { Up-regulation of miR- } \\
1246\end{array}$ & poor OS & - & - & & \\
\hline & $\begin{array}{l}\text { GEO database: } \\
\text { (GSE124678, } \\
\text { GSE70289, } \\
\text { GSE62819) (14 } \\
\text { LSCC tissues and } \\
49 \text { ANCTs) }\end{array}$ & $\begin{array}{l}\text { Up-regulation of miR- } \\
1246\end{array}$ & - & - & - & - & Jing et al. (2020) \\
\hline $\begin{array}{l}\text { Pancreatobiliary } \\
\text { tract cancer }\end{array}$ & $\begin{array}{l}12 \text { pancreatobiliary } \\
\text { tract cancer patients } \\
\text { and } 13 \text { healthy } \\
\text { controls }\end{array}$ & $\begin{array}{l}\text { Up-regulation of miR- } \\
1246\end{array}$ & - & - & - & TaqMan MicroRNA Assays & $\begin{array}{l}\text { Machida et al. } \\
(2016)\end{array}$ \\
\hline \multirow[t]{2}{*}{ Melanoma } & $\begin{array}{l}43 \text { pairs of } \\
\text { melanoma tissues } \\
\text { and ANCTs }\end{array}$ & $\begin{array}{l}\text { Up-regulation of miR- } \\
1246\end{array}$ & - & - & - & $\begin{array}{l}\text { SYBR-Green Premix Ex } \\
\text { Taq II }\end{array}$ & Yu et al. (2020) \\
\hline & $\begin{array}{l}42 \text { melanoma } \\
\text { patients and } 20 \\
\text { healthy controls }\end{array}$ & $\begin{array}{l}\text { Up-regulation of miR- } \\
1246 \text { in melanoma } \\
\text { patients' EVs }\end{array}$ & - & - & metastatic tumor EVs & KAPA SYBR Fast qPCR Kit & $\begin{array}{l}\text { Torii et al. } \\
(2021)\end{array}$ \\
\hline Glioma & 26 glioma patients & & - & - & - & SYBR Premix Ex Taq ${ }^{\mathrm{TM}}$ Kit & $\begin{array}{l}\text { Qian et al. } \\
(2020)\end{array}$ \\
\hline
\end{tabular}


TABLE 3 | (Continued) Results of studies that reported dysregulation of miR-1246 or other genes that interact with miR-1246 in clinical samples.

\begin{tabular}{|c|c|c|c|c|c|c|c|}
\hline Tumor type & Samples & $\begin{array}{l}\text { Expression of miR- } \\
1246 \text { or other genes } \\
\text { (tumor vs. normal) }\end{array}$ & $\begin{array}{c}\text { Kaplan-Meier } \\
\text { analysis (impact of } \\
\text { miR-1246 } \\
\text { dysregulation or } \\
\text { other genes } \\
\text { dysregulation) }\end{array}$ & $\begin{array}{l}\text { Univariate/ } \\
\text { Multivariate cox } \\
\text { regression }\end{array}$ & $\begin{array}{l}\text { Association of } \\
\text { expression of miR- } \\
1246 \text { or expression of } \\
\text { other genes with } \\
\text { clinicopathologic } \\
\text { characteristics }\end{array}$ & $\begin{array}{l}\text { Method for assessment } \\
\text { of miR-1246 expression }\end{array}$ & References \\
\hline & & $\begin{array}{l}\text { Up-regulation of miR- } \\
1246 \text { in GBM than } \\
\text { LGG patients }\end{array}$ & & & & & \\
\hline & $\begin{array}{l}\text { CGGA, GEO } \\
\text { Databases: } \\
\text { (GSE25632, } \\
\text { GSE104554) (311 } \\
\text { glioma patients) }\end{array}$ & $\begin{array}{l}\text { Up-regulation of miR- } \\
1246\end{array}$ & Worse prognosis & $\begin{array}{l}\text { miR-1246 was an } \\
\text { independent risk } \\
\text { factor for OS. }\end{array}$ & Tumor recurrence & - & Ji et al. (2020) \\
\hline \multirow[t]{5}{*}{$\begin{array}{l}\text { Pancreatic } \\
\text { cancer (PC) }\end{array}$} & $\begin{array}{l}\text { Plasma from } 15 \mathrm{PC} \\
\text { patients and } 15 \\
\text { healthy controls }\end{array}$ & $\begin{array}{l}\text { Up-regulation of miR- } \\
1246\end{array}$ & - & - & - & $\begin{array}{l}\text { qScript miRNA cDNA } \\
\text { Synthesis Kit }\end{array}$ & Xu et al. (2017) \\
\hline & $\begin{array}{l}7 \text { PDAC patients, } 4 \\
\text { IPMN patients, } 4 \\
\text { NET patients }\end{array}$ & $\begin{array}{l}\text { Up-regulation of miR- } \\
1246 \text { in patients with } \\
\text { IPMN }\end{array}$ & - & - & - & & \\
\hline & $\begin{array}{l}\text { GEO datasets } \\
\text { (GSE113486, } \\
\text { GSE106817, } \\
\text { GSE59856) }\end{array}$ & $\begin{array}{l}\text { Up-regulation of miR- } \\
1246\end{array}$ & - & - & - & $\begin{array}{l}\text { Hairpin-itTM microRNA RT- } \\
\text { PCR Quantitation Kit }\end{array}$ & Wei et al. (2020) \\
\hline & $\begin{array}{l}120 \text { PC patients, } 40 \\
\text { benign pancreatic } \\
\text { disease controls } \\
\text { (DC) and } 40 \text { healthy } \\
\text { controls }\end{array}$ & $\begin{array}{l}\text { Up-regulation of miR- } \\
1246 \text { in PC than DC } \\
\text { and HC group }\end{array}$ & - & $\begin{array}{l}\text { miR-1246 was } \\
\text { significant and } \\
\text { independent risk } \\
\text { factors for PC }\end{array}$ & Tumor size & & \\
\hline & $\begin{array}{l}\text { Serum from } 34 \text { pairs } \\
\text { of pre- and post- } \\
\text { operation PC } \\
\text { patients }\end{array}$ & $\begin{array}{l}\text { Down-regulation of } \\
\text { miR-1246 after } \\
\text { surgical resection of } \\
\text { malignancies }\end{array}$ & - & - & - & & \\
\hline \multirow[t]{4}{*}{$\begin{array}{l}\text { Ovarian } \\
\text { cancer (OC) }\end{array}$} & $\begin{array}{l}15 \text { OC tissues and } 7 \\
\text { normal ovarian } \\
\text { surface epithelium } \\
\text { tissues }\end{array}$ & $\begin{array}{l}\text { Up-regulation of miR- } \\
1246 \text { in OC exosomes }\end{array}$ & - & - & Paclitaxel-resistant & $\begin{array}{l}\text { PerfeCTa microRNA } \\
\text { Assay Kit }\end{array}$ & $\begin{array}{l}\text { Kanlikilicer et al. } \\
(2018)\end{array}$ \\
\hline & $\begin{array}{l}\text { Serum from } 110 \\
\text { HGSOC patients } \\
\text { and } 52 \text { Healthy } \\
\text { controls }\end{array}$ & $\begin{array}{l}\text { Up-regulation of miR- } \\
1246\end{array}$ & - & - & - & $\begin{array}{l}\text { Rotor-Gene Thermal Cycler } \\
\text { (Qiagen }\end{array}$ & $\begin{array}{l}\text { Todeschini et al. } \\
(2017)\end{array}$ \\
\hline & $\begin{array}{l}\text { serum from } 58 \\
\text { HGSOC patients } \\
\text { and } 13 \text { Healthy } \\
\text { controls }\end{array}$ & $\begin{array}{l}\text { Up-regulation of miR- } \\
1246\end{array}$ & - & - & - & & \\
\hline & $\begin{array}{l}59 \text { high-grade OSC } \\
\text { patients }\end{array}$ & $\begin{array}{l}\text { Up-regulation of miR- } \\
1246\end{array}$ & - & - & - & $\begin{array}{l}\text { TaqMan microRNA reverse } \\
\text { transcription kit }\end{array}$ & Cha et al. (2017) \\
\hline $\begin{array}{l}\text { Clear cell renal cell } \\
\text { carcinoma } \\
\text { (ccRCC) }\end{array}$ & $\begin{array}{l}48 \text { pairs of ccRCC } \\
\text { tissues and ANCTs }\end{array}$ & $\begin{array}{l}\text { Down-regulation of } \\
\text { GABPB1-AS1 (that } \\
\text { sponges miR-1246) }\end{array}$ & better OS & - & $\begin{array}{l}\text { inversely associated with } \\
\text { tumor size, TNM stage, } \\
\text { and Furhman stage }\end{array}$ & Roche PCR system & $\begin{array}{l}\text { Gao et al. } \\
(2020)\end{array}$ \\
\hline $\begin{array}{l}\text { Gastric } \\
\text { cancer (GC) }\end{array}$ & $\begin{array}{l}\text { urine from and } 7 \mathrm{GC} \\
\text { patients and } 3 \\
\text { healthy controls }\end{array}$ & $\begin{array}{l}\text { Up-regulation of miR- } \\
1246\end{array}$ & - & - & - & $\begin{array}{l}\text { Illumina NextSeq } 500 \text { SE50 } \\
(20 \mathrm{M}) \text { sequencing }\end{array}$ & $\begin{array}{l}\text { Qian et al. } \\
\text { (2021b) }\end{array}$ \\
\hline \multirow[t]{2}{*}{$\begin{array}{l}\text { Gallbladder } \\
\text { cancer (GBC) }\end{array}$} & $\begin{array}{l}\text { Serum EVs from } 3 \\
\text { patients with GBC, } 3 \\
\text { with Benign and } 10 \\
\text { healthy controls }\end{array}$ & $\begin{array}{l}\text { Up-regulation of miR- } \\
1246 \text { in GBC than } \\
\text { Benign and healthy } \\
\text { controls }\end{array}$ & - & $\begin{array}{l}\text { Serum EV miR-1246 } \\
\text { was significant } \\
\text { independent } \\
\text { prognostic factor }\end{array}$ & Advanced-stage GBC & - & $\begin{array}{l}\text { Ueta et al. } \\
(2021)\end{array}$ \\
\hline & $\begin{array}{l}\text { GEO database: } \\
\text { GSE104165, } \\
\text { GSE112408 }\end{array}$ & $\begin{array}{l}\text { Up-regulation of miR- } \\
1246 \text { in GBC tissues }\end{array}$ & - & - & - & & \\
\hline Sarcoma & $\begin{array}{l}22 \text { Sarcoma } \\
\text { patients, } 17 \text { DDLPS } \\
\text { patients, and } 3 \text { EWS } \\
\text { patients }\end{array}$ & $\begin{array}{l}\text { Up-regulation of miR- } \\
1246 \text { in DDLPS }\end{array}$ & - & - & - & $\begin{array}{l}\text { miScript }{ }^{\circledR} S Y B R^{\circledR} \text { Green } \\
\text { PCR kit }\end{array}$ & $\begin{array}{l}\text { Kohama et al. } \\
(2021)\end{array}$ \\
\hline
\end{tabular}

adenocarcinomas, IPMN: intraductal papillary mucinous neoplasms, NET: well differentiated neuroendocrine tumors, HGSOC: High-grade serous ovarian carcinoma, OSC: ovarian serous carcinoma, EVs: extracellular vesicles, DDLPS: dedifferentiated liposarcoma, EWS: Ewing's sarcoma).
Diagnostic value of miR-1246 has been validated in different neoplastic disorders (Table 4). The most promising results have been revealed in breast cancer. This miRNA could separate breast cancer patients from healthy controls with area under receiver operating characteristic curve (AUC) of 0.967 (Cui et al., 2018). 
TABLE 4 | Diagnostic value of miR-1246 in cancers (NMRD: non-malignant respiratory diseases, NSCLC: non-small cell lung cancer, ESCC: esophageal squamous cell carcinoma, ETR: Early tumor recurrence, HGSOC: High-grade serous ovarian carcinoma).

\begin{tabular}{|c|c|c|c|c|c|c|c|}
\hline Tumor type & Numbers of clinical samples & Distinguish between & $\begin{array}{l}\text { Area } \\
\text { under } \\
\text { curve }\end{array}$ & $\begin{array}{c}\text { Sensitivity } \\
(\%)\end{array}$ & $\begin{array}{l}\text { Specificity } \\
\text { (\%) }\end{array}$ & $\begin{array}{c}\text { Accuracy } \\
(\%)\end{array}$ & References \\
\hline \multirow[t]{2}{*}{$\begin{array}{l}\text { Colorectal } \\
\text { cancer (CRC) }\end{array}$} & $\begin{array}{l}\text { Sera of } 37 \text { CRC patients and } 30 \\
\text { healthy controls }\end{array}$ & $\begin{array}{l}37 \text { CRC patients vs. healthy } \\
\text { controls }\end{array}$ & - & 100 & 80 & - & $\begin{array}{l}\text { Salah et al. } \\
(2020)\end{array}$ \\
\hline & $\begin{array}{l}\text { Serum samples from } 43 \mathrm{CRC} \\
\text { patients }\end{array}$ & $\begin{array}{l}\text { Chemoresistant CRC patients } \\
\text { vs. chemosensitive group }\end{array}$ & 0.749 & - & - & - & Jin et al. (2019) \\
\hline \multirow[t]{3}{*}{ Lung cancer } & $\begin{array}{l}105 \text { NSCLC patients, } 50 \text { NMRD } \\
\text { patients, and } 50 \text { healthy controls }\end{array}$ & $\begin{array}{l}\text { NSCLC patients vs. healthy } \\
\text { controls }\end{array}$ & 0.827 & - & - & - & $\begin{array}{l}\text { Huang and Qu } \\
\text { (2020) }\end{array}$ \\
\hline & & $\begin{array}{l}\text { NSCLC patients vs. NMRD } \\
\text { patients }\end{array}$ & 0.757 & - & - & - & \\
\hline & $\begin{array}{l}52 \text { NSCLC patients and } 45 \\
\text { healthy controls }\end{array}$ & $\begin{array}{l}\text { NSCLC patients vs. healthy } \\
\text { controls }\end{array}$ & 0.6761 & - & - & - & $\begin{array}{l}\text { Zheng et al. } \\
(2021)\end{array}$ \\
\hline \multirow[t]{6}{*}{ Esophageal cancer } & $\begin{array}{l}\text { Serum from } 55 \text { ESCC patients } \\
\text { and } 39 \text { healthy controls }\end{array}$ & $\begin{array}{l}\text { ESCC patients vs. healthy } \\
\text { controls }\end{array}$ & 0.816 & 72.7 & 69.2 & - & $\begin{array}{l}\text { Hoshino et al. } \\
(2020 \text { a) }\end{array}$ \\
\hline & $\begin{array}{l}\text { Serum from } 101 \text { ESCC patients } \\
\text { and } 34 \text { healthy controls }\end{array}$ & $\begin{array}{l}\text { ESCC patients vs. healthy } \\
\text { controls }\end{array}$ & 0.779 & 71.3 & 70.6 & - & \\
\hline & $\begin{array}{l}101 \text { ESCC patients and } 35 \text { healthy } \\
\text { controls }\end{array}$ & $\begin{array}{l}\text { ESCC patients vs healthy } \\
\text { controls }\end{array}$ & 0.754 & 71.29 & 73.91 & - & $\begin{array}{l}\text { Hoshino et al. } \\
\text { (2020b) }\end{array}$ \\
\hline & $\begin{array}{l}101 \text { ESCC patients and } 46 \text { healthy } \\
\text { controls }\end{array}$ & $\begin{array}{l}\text { ESCC patients vs. healthy } \\
\text { controls }\end{array}$ & 0.754 & 71.3 & 73.9 & - & $\begin{array}{l}\text { Takeshita et al. } \\
\text { (2013) }\end{array}$ \\
\hline & $\begin{array}{l}\text { serum } 72 \text { ESCC patients and } 50 \\
\text { healthy controls }\end{array}$ & $\begin{array}{l}\text { ESCC patients vs. healthy } \\
\text { controls }\end{array}$ & 0.912 & 91.7 & 76.0 & - & $\begin{array}{l}\text { Hoshino et al. } \\
\text { (2021) }\end{array}$ \\
\hline & $\begin{array}{l}\text { urine from } 72 \text { ESCC patients and } \\
50 \text { healthy controls }\end{array}$ & $\begin{array}{l}\text { ESCC patients vs. healthy } \\
\text { controls }\end{array}$ & 0.823 & 90.3 & 62.0 & - & \\
\hline \multirow[t]{2}{*}{$\begin{array}{l}\text { Prostate } \\
\text { cancer (PCa) }\end{array}$} & $\begin{array}{l}26 \text { lymph node metastatic } \mathrm{PCa} \text {, } \\
43 \text { non-metastatic } \mathrm{PCa} \text {, and } 8 \\
\text { healthy controls }\end{array}$ & $\begin{array}{l}\text { Non-metastatic vs. localized } \\
\text { metastatic PCa patients }\end{array}$ & 0.648 & 81 & $\sim 59$ & - & $\begin{array}{l}\text { Bhagirath et al. } \\
\text { (2018) }\end{array}$ \\
\hline & $\begin{array}{l}43 \text { metastatic castration-resistant } \\
\text { PCa cases }\end{array}$ & $\begin{array}{l}\text { Normal and aggressive PCa } \\
\text { patients and normal controls }\end{array}$ & 0.933 & 88.37 & 100 & - & \\
\hline \multirow[t]{6}{*}{ Breast cancer } & $\begin{array}{l}32 \text { trastuzumab-resistant patients } \\
\text { and } 36 \text { trastuzumab sensitive } \\
\text { patients }\end{array}$ & $\begin{array}{l}\text { Trastuzumab-resistant } \\
\text { patients vs. trastuzumab } \\
\text { sensitive patients }\end{array}$ & 0.750 & 78.1 & 75 & - & $\begin{array}{l}\text { Zhang et al. } \\
(2020)\end{array}$ \\
\hline & $\begin{array}{l}\text { Plasma from } 16 \text { breast cancer } \\
\text { patients and } 16 \text { healthy controls }\end{array}$ & $\begin{array}{l}\text { Breast cancer patients vs. } \\
\text { healthy controls }\end{array}$ & 0.69 & - & - & - & $\begin{array}{l}\text { Hannafon et al. } \\
\text { (2016) }\end{array}$ \\
\hline & $\begin{array}{l}\text { serum from } 100 \text { breast cancer } \\
\text { patients and } 40 \text { healthy controls }\end{array}$ & $\begin{array}{l}\text { Breast cancer patients vs. } \\
\text { healthy controls }\end{array}$ & 0.904 & 93.0 & 75.0 & - & Fu et al. (2016) \\
\hline & $\begin{array}{l}\text { Plasma from } 146 \text { breast cancer } \\
\text { patients and } 90 \text { healthy controls }\end{array}$ & $\begin{array}{l}\text { Breast cancer patients vs. } \\
\text { healthy controls }\end{array}$ & 0.95 & 85.0 & 93.0 & 88.0 & $\begin{array}{l}\text { Jang et al. } \\
(2021)\end{array}$ \\
\hline & $\begin{array}{l}\text { Plasma from } 80 \text { breast cancer } \\
\text { patients and } 56 \text { healthy controls }\end{array}$ & $\begin{array}{l}\text { Breast cancer patients vs. } \\
\text { healthy controls }\end{array}$ & 0.963 & 86.0 & 96.0 & 90.0 & \\
\hline & $\begin{array}{l}859 \mathrm{BC} \text { patients and } 1,791 \\
\text { healthy controls }\end{array}$ & $\begin{array}{l}\text { Breast cancer patients vs. } \\
\text { healthy controls }\end{array}$ & 0.967 & 89.8 & 91.7 & - & Cui et al. (2018) \\
\hline \multirow[t]{6}{*}{$\begin{array}{l}\text { Hepatocellular } \\
\text { carcinoma (HCC) }\end{array}$} & $\begin{array}{l}\text { Serum from } 33 \text { primary HCC patients, } \\
22 \text { metastatic liver tumor patients }\end{array}$ & $\begin{array}{l}\text { HCC patients vs. metastatic } \\
\text { liver tumor patients }\end{array}$ & 0.708 & 72.2 & 67.8 & - & $\begin{array}{l}\text { Ahmed et al. } \\
(2019)\end{array}$ \\
\hline & $\begin{array}{l}16 \text { HCC patients and } 27 \text { cirrhosis } \\
\text { patients }\end{array}$ & $\begin{array}{l}\text { HCC patients vs. cirrhotic } \\
\text { patients }\end{array}$ & 0.97 & 86.7 & 84.6 & 85.7 & $\begin{array}{l}\text { Moshiri et al. } \\
(2018)\end{array}$ \\
\hline & $\begin{array}{l}29 \text { HCC patients and } 25 \text { healthy } \\
\text { controls }\end{array}$ & $\begin{array}{l}\text { HCC patients vs. healthy } \\
\text { controls }\end{array}$ & 0.83 & 57.1 & 78.6 & 71.4 & \\
\hline & $\begin{array}{l}\text { Serum from } 50 \text { HCC patients and } \\
50 \text { healthy controls }\end{array}$ & $\begin{array}{l}\text { HCC patients vs. healthy } \\
\text { controls }\end{array}$ & 0.865 & 82.0 & 80.0 & - & $\begin{array}{l}\text { Chen et al. } \\
(2021 b)\end{array}$ \\
\hline & $\begin{array}{l}37 \text { HCC patients with ETR and } 84 \\
\text { HCC patients without ETR }\end{array}$ & $\begin{array}{l}\text { HCC patients with ETR vs. } \\
\text { HCC patients without ETR }\end{array}$ & 0.762 & 54.1 & 77.4 & - & $\begin{array}{l}\text { Chuma et al. } \\
(2019)\end{array}$ \\
\hline & $\begin{array}{l}62 \text { HCC patients received liver } \\
\text { transplantation }\end{array}$ & $\begin{array}{l}\text { High group vs. low group for } \\
\text { tumor recurrence }\end{array}$ & 0.775 & 88.9 & 66.0 & - & $\mathrm{Ng}$ et al. (2016) \\
\hline $\begin{array}{l}\text { Pancreatobiliary } \\
\text { tract cancer }\end{array}$ & $\begin{array}{l}12 \text { pancreatobiliary tract cancer } \\
\text { patients and } 13 \text { healthy controls }\end{array}$ & $\begin{array}{l}\text { Pancreatobiliary tract cancer } \\
\text { patients vs. healthy controls }\end{array}$ & 0.814 & 0.667 & 1.000 & - & $\begin{array}{l}\text { Machida et al. } \\
\text { (2016) }\end{array}$ \\
\hline Ovarian cancer (OC) & $\begin{array}{l}\text { Serum from } 168 \text { HGSOC patients } \\
\text { and } 65 \text { Healthy controls }\end{array}$ & $\begin{array}{l}\text { HGSOC patients vs. Healthy } \\
\text { controls }\end{array}$ & 0.89 & 87 & 77 & 84 & $\begin{array}{l}\text { Todeschini } \\
\text { et al. (2017) }\end{array}$ \\
\hline
\end{tabular}

In hepatocellular carcinoma, miR-1246 could be used as a diagnostic marker for differentiation of cancer status from cirrhosis and healthy controls with AUC values of 0.97 and
0.83 , respectively (Moshiri et al., 2018). Expression level of miR-1246 in serum samples have been shown to distinguish colorectal cancer patients from healthy subjects with sensitivity of 
$100 \%$ and specificity of $80 \%$ (Salah et al., 2020). This miRNA could separate lung cancer patients from healthy controls with AUC value of 0.82 (Huang and Qu, 2020). Moreover, serum and urine levels of miR-1246 could be used as diagnostic markers for esophageal cancer with AUC values of 0.91 and 0.82 , respectively (Hoshino et al., 2021).

\section{DISCUSSION}

miR-1246 is a miRNA with essential impact on carcinogenic events in different tissues. It exerts oncogenic roles in colorectal, breast, renal, oral, laryngeal, pancreatic and ovarian cancers as well as melanoma and glioma. However, in lung, cervical and liver cancers, studies have reported contradictory results regarding the role of miR-1246. Although several targets have been found for miR-1249 using bioinformatics tools and luciferase assay, CCNG2 is the most appreciated target of this miRNA in the context of cancer. miR-1246/CCNG2 axis not only regulates cell proliferation and cell cycle progression, but also is involved in chemoresistant phenotype.

The main mechanism of dysregulation of miR-1246 in cancer is methylation of pri-miR-1246 by methyltransferase METTL3 and modulation of maturation of pri-miR-1246. Unlike other miRNAs, the role of sponging lncRNAs on its expression is less studied.

miR-1246 has been reported to regulate activity of RAF/MEK/ ERK, GSK3 $\beta$, Wnt/ $\beta$-catenin, JAK/STAT, PI3K/AKT, THBS2/ MMP and NOTCH2 pathways. The role of miR-1246 in response to therapeutic modalities has been verified in different settings, indicating its crucial roles in determination of response to targeted therapies, radiotherapy as well as chemotherapy. In fact, miR-1246 can facilitate evolution of cancer through conferring stemness and EMT as well as induction of cell cycle progression and proliferation.

\section{REFERENCES}

Abdelhamed, S., Butler, J. T., Doron, B., Halse, A., Nemecek, E., Wilmarth, P. A., et al. (2019). Extracellular Vesicles Impose Quiescence on Residual Hematopoietic Stem Cells in the Leukemic Niche. EMBO Rep. 20 (7), e47546. doi:10.15252/embr.201847546

Ahmed, E. K., Fahmy, S. A., Effat, H., and Wahab, A. H. A. (2019). Circulating miR-210 and miR-1246 as Potential Biomarkers for Differentiating Hepatocellular Carcinoma from Metastatic Tumors in the Liver. J. Med. Biochem. 38 (2), 109-117. doi:10.2478/jomb-2018-0010

Bhagirath, D., Yang, T. L., Bucay, N., Sekhon, K., Majid, S., Shahryari, V., et al. (2018). microRNA-1246 Is an Exosomal Biomarker for Aggressive Prostate Cancer. Cancer Res. 78 (7), 1833-1844. doi:10.1158/0008-5472.can-17-2069

Cha, S. y., Choi, Y. h., Hwang, S., Jeong, J.-Y., and An, H. J. (2017). Clinical Impact of microRNAs Associated with Cancer Stem Cells as a Prognostic Factor in Ovarian Carcinoma. J. Cancer 8 (17), 3538-3547. doi:10.7150/jca.20348

Chai, S., Ng, K.-Y., Tong, M., Lau, E. Y., Lee, T. K., Chan, K. W., et al. (2016). Octamer 4/microRNA-1246 Signaling axis Drives Wnt/ $\beta$-Catenin Activation in Liver Cancer Stem Cells. Hepatology 64 (6), 2062-2076. doi:10.1002/hep.28821

Chen, J., Yao, D., Zhao, S., He, C., Ding, N., Li, L., et al. (2014). MiR-1246 Promotes SiHa Cervical Cancer Cell Proliferation, Invasion, and Migration through Suppression of its Target Gene Thrombospondin 2. Arch. Gynecol. Obstet. 290 (4), 725-732. doi:10.1007/s00404-014-3260-2
Diagnostic role of miR-1246 has been vastly appraised in different clinical settings, revealing nearly ideal AUC values, particularly in esophageal, prostate, breast, lung, liver, pancreatobiliary tract and ovarian cancers. The AUC, sensitivity and specificity values obtained for miR-1246 in different cancers are far superior to conventional biomarkers in these cancers. Thus, this miRNA represents an appropriate diagnostic biomarker for neoplastic conditions. Since its levels have been decreased following therapeutic interventions, it has additional advantage in patients' follow-up. Although miR-1246 can be a putative therapeutic target for cancer, there is no tissuespecific therapeutic approach designed based on miR-1246 until now.

Taken together, miR-1246 is mostly regarded as an oncogenic miRNA in human cancers, albeit some inconsistencies exist for some types of cancers. The interactions of miR-1249 with other types of non-coding RNAs such as IncRNAs and circular RNAs have not been completely assessed. Identification of such interactions has implications in design of diagnostic panels for different cancers.

\section{CONCLUSIONS AND FUTURE PERSPECTIVES}

miR-1246 is an oncogenic miRNA in several tissues. Therapeutic intervention with its expression or methylation pattern can be regarded as a novel modality. However, it is necessary to design tissue-specific therapeutic approaches.

\section{AUTHOR CONTRIBUTIONS}

SG-F wrote the draft and revised it. MT supervised and designed the study. MS and TK collected the data and designed the figures and tables. All the authors read and approved the submitted version.

Chen, L., Guo, Z., Zhou, Y., Ni, J., Zhu, J., Fan, X., et al. (2021a). microRNA-1246containing Extracellular Vesicles from Acute Myeloid Leukemia Cells Promote the Survival of Leukemia Stem Cells via the LRIG1-Meditated STAT3 Pathway. Aging 13 (10), 13644-13662. doi:10.18632/aging.202893

Chen, S., Fu, Z., Wen, S., Yang, X., Yu, C., Zhou, W., et al. (2021b). Expression and Diagnostic Value of miR-497 and miR-1246 in Hepatocellular Carcinoma. Front. Genet. 12, 790. doi:10.3389/fgene.2021.666306

Chuma, M., Toyoda, H., Matsuzaki, J., Saito, Y., Kumada, T., Tada, T., et al. (2019). Circulating microRNA-1246 as a Possible Biomarker for Early Tumor Recurrence of Hepatocellular Carcinoma. Hepatol. Res. 49 (7), 810-822. doi:10.1111/hepr.13338

Cui, X., Li, Z., Zhao, Y., Song, A., Shi, Y., Hai, X., et al. (2018). Breast Cancer Identification via Modeling of Peripherally Circulating miRNAs. PeerJ 6, e4551. doi:10.7717/peerj.4551

Du, P., Lai, Y. H., Yao, D. S., Chen, J. Y., and Ding, N. (2019). Downregulation of microRNA-1246 Inhibits Tumor Growth and Promotes Apoptosis of Cervical Cancer Cells by Targeting Thrombospondin-2. Oncol. Lett. 18 (3), 2491-2499. doi:10.3892/ol.2019.10571

Fu, L., Li, Z., Zhu, J., Wang, P., Fan, G., Dai, Y., et al. (2016). Serum Expression Levels of microRNA-382-3p, $-598-3 p,-1246$ and -184 in Breast Cancer Patients. Oncol. Lett. 12 (1), 269-274. doi:10.3892/ol.2016.4582

Fujita, K., Iwama, H., Oto, T., Okura, R., Kobayashi, K., Takano, J., et al. (2015). Galectin-9 Suppresses the Growth of Hepatocellular Carcinoma via Apoptosis In Vitro and In Vivo. Int. J. Oncol. 46 (6), 2419-2430. doi:10.3892/ijo.2015.2941 
Gao, S., Zhang, F., Sun, H., and Yang, X. (2020). LncRNA GA-Binding Protein Transcription Factor Subunit Beta-1 Antisense RNA 1 Inhibits Renal Carcinoma Growth through an MiR-1246/Phosphoenolpyruvate Carboxykinase 1 Pathway. Ott 13, 6827-6836. doi:10.2147/ott.s257275

Guo, S., Chen, J., Chen, F., Zeng, Q., Liu, W.-L., and Zhang, G. (2021). Exosomes Derived from Fusobacterium Nucleatum-Infected Colorectal Cancer Cells Facilitate Tumour Metastasis by Selectively Carrying miR-1246/92b-3p/27a3p and CXCL16. Gut 70 (8), 1507-1519. doi:10.1136/gutjnl-2020-321187

Handa, T., Kuroha, M., Nagai, H., Shimoyama, Y., Naito, T., Moroi, R., et al. (2021). Liquid Biopsy for Colorectal Adenoma: Is the Exosomal miRNA Derived from Organoid a Potential Diagnostic Biomarker? Clin. Transl Gastroenterol. 12 (5), e00356. doi:10.14309/ctg.0000000000000356

Hannafon, B. N., Trigoso, Y. D., Calloway, C. L., Zhao, Y. D., Lum, D. H., Welm, A. L., et al. (2016). Plasma Exosome microRNAs Are Indicative of Breast Cancer. Breast Cancer Res. 18 (1), 90-14. doi:10.1186/s13058-016-0753-x

Hasegawa, S., Eguchi, H., Nagano, H., Konno, M., Tomimaru, Y., Wada, H., et al. (2014). MicroRNA-1246 Expression Associated with CCNG2-Mediated Chemoresistance and Stemness in Pancreatic Cancer. Br. J. Cancer 111 (8), 1572-1580. doi:10.1038/bjc.2014.454

Hoshino, I., Yokota, H., Ishige, F., Iwatate, Y., Takeshita, N., Nagase, H., et al. (2020b). Radiogenomics Predicts the Expression of microRNA-1246 in the Serum of Esophageal Cancer Patients. Sci. Rep. 10 (1), 2532-2538. doi:10.1038/ s41598-020-59500-7

Hoshino, I., Ishige, F., Iwatate, Y., Gunji, H., Kuwayama, N., Nabeya, Y., et al. (2021). Cell-free microRNA-1246 in Different Body Fluids as a Diagnostic Biomarker for Esophageal Squamous Cell Carcinoma. Plos one 16 (3), e0248016. doi:10.1371/journal.pone.0248016

Hoshino, I., Ishige, F., Iwatate, Y., Gunji, H., Shiratori, F., Kuwayama, N., et al. (2020a). Usefulness of Serum miR-1246/miR-106b R-atio in P-atients with E-sophageal S-quamous C-ell C-arcinoma. Oncol. Lett. 20 (6), 350. doi:10.3892/ol.2020.12213

Huang, D., and Qu, D. (2020). Early Diagnostic and Prognostic Value of Serum Exosomal miR-1246 in Non-small Cell Lung Cancer. Int. J. Clin. Exp. Pathol. 13 (7), 1601-1607.

Huang, J.-L., Fu, Y.-P., Gan, W., Liu, G., Zhou, P.-Y., Zhou, C., et al. (2020a). Hepatic Stellate Cells Promote the Progression of Hepatocellular Carcinoma through microRNA-1246-Rora-Wnt/ $\beta$-Catenin axis. Cancer Lett. 476, 140-151. doi:10.1016/j.canlet.2020.02.012

Huang, Q., Hsueh, C. Y., Guo, Y., Wu, X. F., Li, J. Y., and Zhou, L. (2020b). Lack of miR-1246 in Small Extracellular Vesicle Blunts Tumorigenesis of Laryngeal Carcinoma Cells by Regulating Cyclin G2. IUBMB life 72 (7), 1491-1503. doi:10.1002/iub.2274

Huang, S., Luo, S., Gong, C., Liang, L., Xiao, Y., Li, M., et al. (2021). MTTL3 Upregulates microRNA-1246 to Promote Occurrence and Progression of NSCLC via Targeting Paternally Expressed Gene 3. Mol. Ther. - Nucleic Acids 24, 542-553. doi:10.1016/j.omtn.2021.02.020

Huang, S., Wei, Y.-K., Kaliamurthi, S., Cao, Y., Nangraj, A. S., Sui, X., et al. (2020c). Circulating miR-1246 Targeting UBE2C, TNNI3, TRAIP, UCHL1 Genes and Key Pathways as a Potential Biomarker for Lung Adenocarcinoma: Integrated Biological Network Analysis. Jpm 10 (4), 162. doi:10.3390/jpm10040162

Jang, J. Y., Kim, Y. S., Kang, K. N., Kim, K. H., Park, Y. J., and Kim, C. W. (2021). Multiple microRNAs as Biomarkers for Early Breast Cancer Diagnosis. Mol. Clin. Oncol. 14 (2), 31. doi:10.3892/mco.2020.2193

Ji, B., Chen, L., Cai, Q., Guo, Q., Chen, Z., and He, D. (2020). Identification of an 8miRNA Signature as a Potential Prognostic Biomarker for Glioma. PeerJ 8, e9943. doi:10.7717/peerj.9943

Jin, G., Liu, Y., Zhang, J., Bian, Z., Yao, S., Fei, B., et al. (2019). A Panel of Serum Exosomal microRNAs as Predictive Markers for Chemoresistance in Advanced Colorectal Cancer. Cancer Chemother. Pharmacol. 84 (2), 315-325. doi:10.1007/s00280-019-03867-6

Jing, Z., Guo, S., Zhang, P., and Liang, Z. (2020). LncRNA-Associated ceRNA Network Reveals Novel Potential Biomarkers of Laryngeal Squamous Cell Carcinoma. Technology Cancer Res. Treat. 19, 1533033820985787. doi:10.1177/1533033820985787

Kanlikilicer, P., Bayraktar, R., Denizli, M., Rashed, M. H., Ivan, C., Aslan, B., et al. (2018). Exosomal miRNA Confers Chemo Resistance via Targeting Cav1/p-gp/ M2-type Macrophage axis in Ovarian Cancer. EBioMedicine 38, 100-112. doi:10.1016/j.ebiom.2018.11.004

Kim, G., An, H.-J., Lee, M.-J., Song, J.-Y., Jeong, J.-Y., Lee, J.-H., et al. (2016). Hsa-miR1246 and Hsa-miR-1290 Are Associated with Stemness and Invasiveness of Nonsmall Cell Lung Cancer. Lung cancer 91, 15-22. doi:10.1016/j.lungcan.2015.11.013
Kim, J.-H., Ahn, J.-H., and Lee, M. (2017). Upregulation of microRNA-1246 Is Associated with BRAF Inhibitor Resistance in Melanoma Cells with Mutant BRAF. Cancer Res. Treat. 49 (4), 947-959. doi:10.4143/crt.2016.280

Kohama, I., Asano, N., Matsuzaki, J., Yamamoto, Y., Yamamoto, T., Takahashi, R.-U., et al. (2021). Comprehensive Serum and Tissue microRNA Profiling in Dedifferentiated Liposarcoma. Oncol. Lett. 22 (2), 1-8. doi:10.3892/ol.2021.12884

Li, X. J., Ren, Z. J., Tang, J. H., and Yu, Q. (2017). Exosomal MicroRNA MiR-1246 Promotes Cell Proliferation, Invasion and Drug Resistance by Targeting CCNG2 in Breast Cancer. Cell Physiol Biochem 44 (5), 1741-1748. doi:10.1159/000485780

Liao, L., Wang, J., Ouyang, S., Zhang, P., Wang, J., and Zhang, M. (2015). Expression and Clinical Significance of microRNA-1246 in Human Oral Squamous Cell Carcinoma. Med. Sci. Monit. 21, 776-781. doi:10.12659/MSM.892508

Lin, S.-S., Peng, C.-Y., Liao, Y.-W., Chou, M.-Y., Hsieh, P.-L., and Yu, C.-C. (2018). miR-1246 Targets CCNG2 to Enhance Cancer Stemness and Chemoresistance in Oral Carcinomas. Cancers 10 (8), 272. doi:10.3390/cancers10080272

Lu, X., Chen, L., Chen, Y., Shao, Q., and Qin, W. (2015). Bafilomycin A1 Inhibits the Growth and Metastatic Potential of the BEL-7402 Liver Cancer and HO8910 Ovarian Cancer Cell Lines and Induces Alterations in Their microRNA Expression. Exp. Ther. Med. 10 (5), 1829-1834. doi:10.3892/etm.2015.2758

Luo, M., Zhang, Q., Xia, M., Hu, F., Ma, Z., Chen, Z., et al. (2018). Differential Coexpression and Regulatory Network Analysis Uncover the Relapse Factor and Mechanism of T Cell Acute Leukemia. Mol. Ther. - Nucleic Acids 12, 184-194. doi:10.1016/j.omtn.2018.05.003

Machida, T., Tomofuji, T., Maruyama, T., Yoneda, T., Ekuni, D., Azuma, T., et al. (2016). miR-1246 and miR-4644 in Salivary Exosome as Potential Biomarkers for Pancreatobiliary Tract Cancer. Oncol. Rep. 36 (4), 2375-2381. doi:10.3892/or.2016.5021

Morin, R. D., O'Connor, M. D., Griffith, M., Kuchenbauer, F., Delaney, A., Prabhu, A.-L., et al. (2008). Application of Massively Parallel Sequencing to microRNA Profiling and Discovery in Human Embryonic Stem Cells. Genome Res. 18 (4), 610-621. doi:10.1101/gr.7179508

Moshiri, F., Salvi, A., Gramantieri, L., Sangiovanni, A., Guerriero, P., De Petro, G., et al. (2018). Circulating miR-106b-3p, miR-101-3p and miR-1246 as Diagnostic Biomarkers of Hepatocellular Carcinoma. Oncotarget 9 (20), 15350-15364. doi:10.18632/oncotarget.24601

Nagai, H., Kuroha, M., Handa, T., Karasawa, H., Ohnuma, S., Naito, T., et al. (2021). Comprehensive Analysis of microRNA Profiles in Organoids Derived from Human Colorectal Adenoma and Cancer. Digestion 102 (6), 860-869. doi: $10.1159 / 000513882$

Nagamitsu, Y., Nishi, H., Sasaki, T., Takaesu, Y., Terauchi, F., and Isaka, K. (2016). Profiling Analysis of Circulating microRNA Expression in Cervical Cancer. Mol. Clin. Oncol. 5 (1), 189-194. doi:10.3892/mco.2016.875

Nakashima, H., Yoshida, R., Hirosue, A., Kawahara, K., Sakata, J., Arita, H., et al. (2019). Circulating miRNA-1290 as a Potential Biomarker for Response to Chemoradiotherapy and Prognosis of Patients with Advanced Oral Squamous Cell Carcinoma: A Single-center Retrospective Study. Tumour Biol. 41 (3), 1010428319826853. doi:10.1177/1010428319826853

Ng, K. T.-P., Lo, C. M., Wong, N., Li, C. X., Qi, X., Liu, X. B., et al. (2016). Earlyphase Circulating miRNAs Predict Tumor Recurrence and Survival of Hepatocellular Carcinoma Patients after Liver Transplantation. Oncotarget 7 (15), 19824-19839. doi:10.18632/oncotarget.7627

Ogata-Kawata, H., Izumiya, M., Kurioka, D., Honma, Y., Yamada, Y., Furuta, K., et al. (2014). Circulating Exosomal microRNAs as Biomarkers of colon Cancer. PloS one 9 (4), e92921. doi:10.1371/journal.pone.0092921

Patel, S. B., and Bellini, M. (2008). The Assembly of a Spliceosomal Small Nuclear Ribonucleoprotein Particle. Nucleic Acids Res. 36 (20), 6482-6493. doi:10.1093/ nar/gkn658

Peng, W., Li, J., Chen, R., Gu, Q., Yang, P., Qian, W., et al. (2019). Upregulated METTL3 Promotes Metastasis of Colorectal Cancer via miR-1246/SPRED2/ MAPK Signaling Pathway. J. Exp. Clin. Cancer Res. 38 (1), 1408-1424. doi:10.1186/s13046-019-1408-4

Qian, M., Chen, Z., Guo, X., Wang, S., Zhang, Z., Qiu, W., et al. (2021a). Exosomes Derived from Hypoxic Glioma Deliver miR-1246 and miR-10b-5p to Normoxic Glioma Cells to Promote Migration and Invasion. Lab. Invest. 101 (5), 612-624. doi:10.1038/s41374-020-00522-0

Qian, M., Wang, S., Guo, X., Wang, J., Zhang, Z., Qiu, W., et al. (2020). Hypoxic Glioma-Derived Exosomes Deliver microRNA-1246 to Induce M2 Macrophage Polarization by Targeting TERF2IP via the STAT3 and NF-Kb Pathways. Oncogene 39 (2), 428-442. doi:10.1038/s41388-019-0996-y 
Qian, X., Xie, F., Wei, H., and Cui, D. (2021b). Identification of Key Circulating Exosomal microRNAs in Gastric Cancer. Front. Oncol. 11, 693360. doi:10.3389/ fonc. 2021.693360

Sakha, S., Muramatsu, T., Ueda, K., and Inazawa, J. (2016). Exosomal microRNA miR-1246 Induces Cell Motility and Invasion through the Regulation of DENND2D in Oral Squamous Cell Carcinoma. Sci. Rep. 6 (1), 1-11. doi:10.1038/srep38750

Salah, M., Shaheen, I., El-Shanawany, P., Eid Saad, N., Saad, R., El Guibaly, M., et al. (2020). Detection of miR-1246, miR-23a and miR-451 in Sera of Colorectal Carcinoma Patients: a Case-Control Study in Cairo University Hospital. Afr. H. Sci. 20 (3), 1283-1291. doi:10.4314/ahs.v20i3.33

Sun, Z., Meng, C., Wang, S., Zhou, N., Guan, M., Bai, C., et al. (2014). MicroRNA1246 Enhances Migration and Invasion through CADM1 in Hepatocellular Carcinoma. BMC cancer 14 (1), 2407-2416. doi:10.1186/1471-2407-14-616

Takeshita, N., Hoshino, I., Mori, M., Akutsu, Y., Hanari, N., Yoneyama, Y., et al. (2013). Serum microRNA Expression Profile: miR-1246 as a Novel Diagnostic and Prognostic Biomarker for Oesophageal Squamous Cell Carcinoma. $\mathrm{Br}$. J. Cancer 108 (3), 644-652. doi:10.1038/bjc.2013.8

Toden, S., Kunitoshi, S., Cardenas, J., Gu, J., Hutchins, E., Van Keuren-Jensen, K., et al. (2019). Cancer Stem Cell-Associated miRNAs Serve as Prognostic Biomarkers in Colorectal Cancer. JCI insight 4 (6). doi:10.1172/jci.insight.125294

Todeschini, P., Salviato, E., Paracchini, L., Ferracin, M., Petrillo, M., Zanotti, L., et al. (2017). Circulating miRNA Landscape Identifies miR-1246 as Promising Diagnostic Biomarker in High-Grade Serous Ovarian Carcinoma: a Validation across Two Independent Cohorts. Cancer Lett. 388, 320-327. doi:10.1016/ j.canlet.2016.12.017

Torii, C., Maishi, N., Kawamoto, T., Morimoto, M., Akiyama, K., Yoshioka, Y., et al. (2021). miRNA-1246 in Extracellular Vesicles Secreted from Metastatic Tumor Induces Drug Resistance in Tumor Endothelial Cells. Sci. Rep. 11 (1), 13502-13516. doi:10.1038/s41598-021-92879-5

Ueta, E., Tsutsumi, K., Kato, H., Matsushita, H., Shiraha, H., Fujii, M., et al. (2021). Extracellular Vesicle-Shuttled miRNAs as a Diagnostic and Prognostic Biomarker and Their Potential Roles in Gallbladder Cancer Patients. Sci. Rep. 11 (1), 12298-12313. doi:10.1038/s41598-021-91804-0

Wang, M., Ji, S., Shao, G., Zhang, J., Zhao, K., Wang, Z., et al. (2018a). Effect of Exosome Biomarkers for Diagnosis and Prognosis of Breast Cancer Patients. Clin. Transl Oncol. 20 (7), 906-911. doi:10.1007/s12094-017-1805-0

Wang, S., Zeng, Y., Zhou, J.-M., Nie, S.-L., Peng, Q., Gong, J., et al. (2016). MicroRNA-1246 Promotes Growth and Metastasis of Colorectal Cancer Cells Involving CCNG2 Reduction. Mol. Med. Rep. 13 (1), 273-280. doi:10.3892/ mmr.2015.4557

Wang, Y., Zhang, C., Zhang, P., Guo, G., Jiang, T., Zhao, X., et al. (2018b). Serum Exosomal microRNAs Combined with Alpha-Fetoprotein as Diagnostic Markers of Hepatocellular Carcinoma. Cancer Med. 7 (5), 1670-1679. doi:10.1002/cam4.1390

Wei, J., Yang, L., Wu, Y.-n., and Xu, J. (2020). Serum miR-1290 and miR-1246 as Potential Diagnostic Biomarkers of Human Pancreatic Cancer. J. Cancer 11 (6), 1325-1333. doi:10.7150/jca.38048

Xie, B., Li, L., Zhang, Z., Zhao, L., Cheng, J., Zhou, C., et al. (2021). MicroRNA-1246 by Targeting AXIN2 and GSK-3 $\beta$ Overcomes Drug Resistance and Induces Apoptosis in Chemo-Resistant Leukemia Cells. J. Cancer 12 (14), 4196-4208. doi:10.7150/jca.58522

Xu, X., Cao, L., Zhang, Y., Lian, H., Sun, Z., and Cui, Y. (2018). MicroRNA-1246 Inhibits Cell Invasion and Epithelial Mesenchymal Transition Process by Targeting CXCR4 in Lung Cancer Cells. Cbm 21 (2), 251-260. doi:10.3233/cbm-170317

Xu, Y.-F., Hannafon, B. N., Khatri, U., Gin, A., and Ding, W.-Q. (2019). The Origin of Exosomal miR-1246 in Human Cancer Cells. RNA Biol. 16 (6), 770-784. doi:10.1080/15476286.2019.1585738
Xu, Y.-F., Hannafon, B. N., Zhao, Y. D., Postier, R. G., and Ding, W.-Q. (2017) Plasma Exosome miR-196a and miR-1246 Are Potential Indicators of Localized Pancreatic Cancer. Oncotarget 8 (44), 77028-77040. doi:10.18632/ oncotarget.20332

Yang, F., Xiong, H., Duan, L., Li, Q., Li, X., and Zhou, Y. (2019). MiR-1246 Promotes Metastasis and Invasion of A549 Cells by Targeting GSK-3 $\beta$ Mediated Wnt/ $\beta$-Catenin Pathway. Cancer Res. Treat. 51 (4), 1420-1429. doi: $10.4143 /$ crt.2018.638

Yang, Y., Xie, Y. J., Xu, Q., Chen, J. X., Shan, N. C., and Zhang, Y. (2015). Downregulation of miR-1246 in Cervical Cancer Tissues and its Clinical Significance. Gynecol. Oncol. 138 (3), 683-688. doi:10.1016/j.ygyno.2015.06.015

Yin, C., Zheng, X., Xiang, H., Li, H., Gao, M., Meng, X., et al. (2019). Differential Expression Profile Analysis of Cisplatin-regulated miRNAs in a H-uman G-astric C-ancer C-ell L-ine. Mol. Med. Rep. 20 (2), 1966-1976. doi:10.3892/mmr.2019.10430

Yu, Y., Yu, F., and Sun, P. (2020). MicroRNA-1246 Promotes Melanoma Progression through Targeting FOXA2. Ott 13, 1245-1253. doi:10.2147/ott.s234276

Yuan, D., Xu, J., Wang, J., Pan, Y., Fu, J., Bai, Y., et al. (2016). Extracellular miR1246 Promotes Lung Cancer Cell Proliferation and Enhances Radioresistance by Directly Targeting DR5. Oncotarget 7 (22), 32707-32722. doi:10.18632/ oncotarget.9017

Zhang, B., Chen, J., Ren, Z., Chen, Y., Li, J., Miao, X., et al. (2013). A Specific miRNA Signature Promotes Radioresistance of Human Cervical Cancer Cells. Cancer Cell Int 13 (1), 118-8. doi:10.1186/1475-2867-13-118

Zhang, Q., Cao, L.-Y., Cheng, S.-J., Zhang, A.-M., Jin, X.-S., and Li, Y. (2015). p53induced microRNA-1246 Inhibits the Cell Growth of Human Hepatocellular Carcinoma Cells by Targeting NFIB. Oncol. Rep. 33 (3), 1335-1341. doi:10.3892/or.2015.3715

Zhang, Y., Liao, J. M., Zeng, S. X., and Lu, H. (2011). p53 Downregulates Down Syndrome-associated DYRK1A through miR-1246. EMBO Rep. 12 (8), 811-817. doi:10.1038/embor.2011.98

Zhang, Z., Zhang, L., Yu, G., Sun, Z., Wang, T., Tian, X., et al. (2020). Exosomal miR-1246 and miR-155 as Predictive and Prognostic Biomarkers for Trastuzumab-Based Therapy Resistance in HER2-Positive Breast Cancer. Cancer Chemother. Pharmacol. 86 (6), 761-772. doi:10.1007/s00280-02004168-z

Zheng, Q., Ding, H., Wang, L., Yan, Y., Wan, Y., Yi, Y., et al. (2021). Circulating Exosomal miR-96 as a Novel Biomarker for Radioresistant Non-small-cell Lung Cancer. J. Oncol. 2021, 1-8. doi:10.1155/2021/5893981

Conflict of Interest: The authors declare that the research was conducted in the absence of any commercial or financial relationships that could be construed as a potential conflict of interest.

Publisher's Note: All claims expressed in this article are solely those of the authors and do not necessarily represent those of their affiliated organizations, or those of the publisher, the editors and the reviewers. Any product that may be evaluated in this article, or claim that may be made by its manufacturer, is not guaranteed or endorsed by the publisher.

Copyright (c) 2022 Ghafouri-Fard, Khoshbakht, Hussen, Taheri and Samadian. This is an open-access article distributed under the terms of the Creative Commons Attribution License (CC BY). The use, distribution or reproduction in other forums is permitted, provided the original author(s) and the copyright owner(s) are credited and that the original publication in this journal is cited, in accordance with accepted academic practice. No use, distribution or reproduction is permitted which does not comply with these terms. 